\title{
KARAKTERISASI DAN INTERAKSI MOLEKULAR ASAM SULFAT
}

\author{
Selfi Monica Aura1 ${ }^{1}$, Rahadian Zainul ${ }^{2}$ \\ ${ }^{1}$ Student Chemistry Education, FMIPA, State University Of Padang \\ ${ }^{2}$ Physical Chemistry Education, FMIPA, State University Of padang \\ E-mail: ${ }^{1}$ Selfyaura@gmail.com, \\ ${ }^{2}$ rahadianzaiphd@yahoo.com
}

\begin{abstract}
Abstrak. Asam sulfat merupakan asam mineral (anorganik) yang kuat dan larut dalam air pada semua perbandingan yang ada. zat ini memiliki banyak kegunaan terutama bidang industry. Penelitian ini bertujuan untuk menganalisis interaksi molekuler dan karakterisasi dari asam sulfat. Metode yang digunakan adalah penggunaan aplikasi Chemdraw 8.0(komputasi), penulusuran literature dengan endnote X7,serta perhitungan matematis. Untuk mengetahui karakterisasi, sintesis, mobilitas, konduktivitas, viskositas, kecepatan hanyut dan interaksi molekul dengan menggunakan rumus dan data dari hasil review jurnal penelitian yang berkaitan dengan asam sulfat seperti tahapan pada fishbone. Asam sulfat mempunyai termokimia dalam fase liquid dengan $\Delta \mathrm{H}$ sebesar $-843,99$ $\mathrm{kj} / \mathrm{mol}, \Delta \mathrm{G}$ sebesar 109,699 kj/mol, $\mathrm{S}^{0}$ sebesar 156,9 j/mol.k, dan Cp sebesar 0,418961 kj/mol.k. interaksi yang terjadi pada ion $\mathrm{H}_{2} \mathrm{SO}_{4}$ dapat diperhatikan melalui beberapa parameter, diantaranya adalah konduktivitas,mobilitas, serta kecepatan hanyut ionnya. Konduktivitas dari $\mathrm{H}_{2} \mathrm{SO}_{4}$ dipengaruhi oleh konsentrasi yaitu semakin banyak ion yang ada dalam suatu larutan maka mobilitas ion yang juga berhubungan dengan kecepatan hanyut dalam larutan akan semakin berkurang sehingga nilai konduktivitas akan menurun. konduktivitas asam sulfat semakin bertambah seiring dengan pertambahan konsentrasi. Berdasarkan metode komputasi dengan chem.office 3D, energy total yang dibutuhkan $\mathrm{H}_{2} \mathrm{SO}_{4}$ utnuk bergerak sebesar $92,629 \mathrm{kcal} / \mathrm{mol}$ $\mathrm{kcal} / \mathrm{mol}$ pada suhu $300 \mathrm{~K}$ dengan gradient yaitu 66,051 .
\end{abstract}

Kata Kunci: Asam Sulfat, karakterisasi,interaksi molekul

\section{Pendahuluan}

Asam sulfat murni yang tidak diencerkan tidak dapat ditemukan secara alami di bumi karena sifatnya higroskopis ${ }^{(190 ; 191)}$. Asam sulfat terbentuk secara alami melalui oksidasi ${ }^{(186,187)}$ mineral sulfida,misalnya besi sulfida. Air asam hasil oksidasi ini mampu melarutkan logam-logam yang ada dalam bijih sulfida,yang menghasilkan uap berwarna cerah yang beracun.

Apabila air ditambahan asam sulfat pekat,maka akan mendidih. Jika melarutkan asam sulfat pekat, tambahkan asam sulfat pekat itu kedalam air, bukan air yang dimasukkan kedalam asam sulfat. Hal ini dilakukan karena asam sulfat bersifat mengeringkan. Seperti reaksi berikut:

$\mathrm{H}_{2} \mathrm{SO}_{4}+\mathrm{H}_{2} \mathrm{O} \rightarrow \mathrm{H}_{3} \mathrm{O}^{+}+\mathrm{HSO}_{4}^{-}$

Asam sulfat merupakan zat pengering yang baik. asam sulfat digunakan dalam pengolahan kebanyakan buah-buah kering.di atmosfer,asam sulfat merupakan salah satu bahan kimia yang menyebabkan hujan asam ${ }^{(45 ; 192)}$. Tak mudah membayangkan bahan kimia yang sangat aktif seperti asam sulfat ini adalah bahan kimia yang banyak dipakai dan merupakan produk yang penting. Zat ini digunakan sebagai bahan untuk pembuatan garam-garam sulfat dan untuk 
sulfonasi,namun sering digunakan karena merupakan asam ${ }^{(188)}$ anorganik yang agak kuat dan lumayan murah.

Bahan kimia seperti asam sulfat ini sering dipakai di industry, namun pada produk akhir asam sulfat itu jarang muncul.asam sulfat dipakai dalam pembuatan pupuk, plat timah, pengolahan minyak, dan dalam pewarna tekstil.

Di bagian atas atmosfer venus yang lebih dingin, terdapat asam sulfat dalam keadaan cair. Awan asam sulfat yang tebal menghalangi pandangan permukaan venus saat dipandang dari atas. Awan permanen venus tersebut menghasilkan hujan asam yang pekat sama halnya atmosfer bumi yang menghasilkan air hujan.

Atmosfer venus menunjukan adanya siklus asam sulfat. Setelah tetesan hujan asam sulfat jatuh kelapisan atmosfer yang lebih panas, asam sulfat akan dipanaskan dan melepaskan uap air, sehingga asam sulfat tersebut menjadi lebih pekat.

Ketika mencapai temperature ${ }^{(226,123)}$ lebih dari $300^{\circ} \mathrm{C}$, asam sulfat mulai berdekomposisi menjadi sulphur trioksida dan air. Sulphur trioksida sangatlah reaktif dan berdispsiasi menjadi sulphur dioksida dan oksigen atomic, yang akan kemudian mengoksidasi karbon monoksida menjadi karbondioksida.sulfur dioksida dan uap air kemudian naik secara arus konveksi dari lapisan tengah atmosfer menuju lapisan atas, dimana keduanya akan diubah lagi menjadi asam sulfat dan ini berulang lagi kemudian.

Asam $^{(127)}$ dikenal sebagai minyak vitriol, diciptakan oleh jabir bin hayyan pada abad ke delapan. Kemudian helmont membuatnya dengan destilasi destruktif vitriol hijau dengan membakar belerang. Kemudian belerang dan kalium nitrat digunakan untuk membuat asam sulfat pada abad ke-17. Pada abad itu,Roebuck telah menemukan proses kamar timbale, namun sekarang proses ini sudah kuno. Philips memperkenlkan penemuan proses kontak yang modern, yaitu dengan melewatkan campuran sulfur dioksida dan udara melalui katalis, kemudian diikuti oleh absorpsi sulfur trioksida didalam asam sulfat 98,5\% sampai $99 \%$.

Penelitian ini bertujuan untuk mengetahui karakteristik ${ }^{(125,172,133,135)}$ dan interaksi antar molekul dari asam sulfat dengan menggunakan aplikasi ChemOffice 8.0 dan juga pemanfaatan dan sifat-sifat serta bahaya dari asam sulfat ini.

\section{Metode}

Metode $^{(189,190,201,143,110)}$ yang digunakan adalah penggunaan aplikasi chemdraw (komputasi), penelusuran literature dengan endnote $\mathrm{X} 7$, serta perhitungan matematis. Untuk penelusuran literature

1. pilih aplikasi endnote $x 7$, lalu klik online search pilih pubmed NLM

2. lalu pilih jenis referensi yaitu Ann Rev Physical Chem

3. dalam mencari referensi, pilih Any Field

4. setelah referensi didapatkan, lalu disitasi ke word

dilakukan beberapa langkah dan tahap demi tahap seperti yang terlihat pada fishbond dibawah untuk analisis ${ }^{(111,112,242,93,94,95,96,97)}$ lebih lanjut mengenai senyawa asam sulfat.

Beberapa tahapan yang dilakukan untuk penelitian ini, yaitu analisis molecular ${ }^{(81)} \mathrm{H}_{2} \mathrm{SO}_{4}$ secara 3D dengan menggunakan ChemDraw Ultra 8.0 dan selanjutnya dengan Chem3D Ultra 8.0. 


\section{Pembahasan}

\subsection{Sifat senyawa asam sulfat}

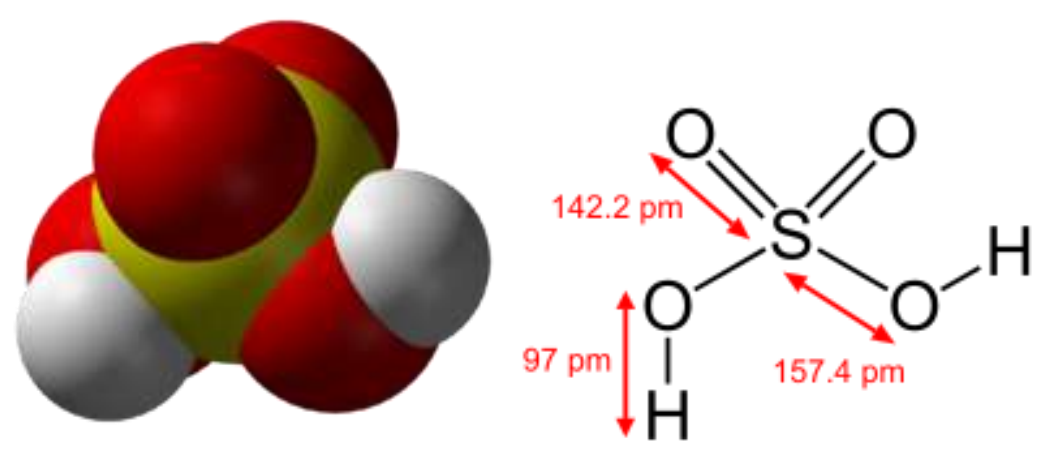

Struktur Asam Sulfat | sulfuric acid structure

Gambar 1. Asam Sulfat

Sumber 1. https://id.wikipedia.org/wiki/Asam_sulfat

Asam sulfat mempunyai rumus kimia $\mathrm{H}_{2} \mathrm{SO}_{4}$, yang merupakan asam mineral(anorganik) yang kuat. Zat ini larut ${ }^{(175)}$ dalam air ${ }^{(228)}$ pada semua perbandingan. Asam sulfat $100 \%$ dapat dibuat namun ia akan melepaskan $\mathrm{SO}_{3}$ pada titik didihnya dan menghasilkan asam $98,3 \%$. Asam sulfat $98 \%$ umumnya disebut sebagai asam sulfat pekat. Asam sulfat murni berupa cairan ${ }^{(131)}$ bening seperti minyak dan karena itu dinamakan pada dahulu kala sebagai minyak vitriol.<smiles>O=S(=O)(O)O</smiles>

sulfuric acid

Gambar 2. Molekul $\mathrm{H}_{2} \mathrm{SO}_{4}$ dalam 2 dimensi (chem.office 2D version 8.0, perkinelmer informatics. Inc, 2015)

Asam sulfat anhidrat adalah cairan yang bersifat ${ }^{(156)}$ polar. Asam sulfat memiliki tetapan dielektrik 100. Asam sulfat memiliki titik didih $337^{\circ} \mathrm{C}(610$ K),titik lebur $10^{\circ} \mathrm{C}(283 \mathrm{~K})$ dan massa molar 98,08 g/mol. Asam sulfat juga memiliki tekanan uap $<10 \mathrm{~Pa}$ pada $20^{\circ} \mathrm{C}$ (diabaikan), keasaman 1,98 pada suhu kamar dan viskositas $26,7 \mathrm{cP}\left(20^{\circ} \mathrm{C}\right)$.

Reaksi hidrasi ${ }^{(193 ; 194)}$ asam sulfat sangat eksotermik. Air memiliki massa jenis yang lebih rendah dari asam sulfat dan cenderung mengapung diatasnya, sehingga jika air ditambahkan kedalam asam sulfat, ia akan dapat mendidih dan bereaksi dengan keras.reaksi yang terbentuk:

$$
\begin{aligned}
& \mathrm{H} 2 \mathrm{SO} 4+\mathrm{H} 2 \mathrm{O} \rightarrow \mathrm{H} 3 \mathrm{O}++\mathrm{HSO} 4- \\
& \mathrm{HSO} 4-+\mathrm{H} 2 \mathrm{O} \rightarrow \mathrm{H} 3 \mathrm{O}++\mathrm{SO} 42-
\end{aligned}
$$


Asam sulfat adalah zat pendehidrasi yang baik,digunakan untuk mengeringkan buah-buahan.Asam sulfat bereaksi dengan basa menghasilkan garam sulfat,contoh:

$$
\mathrm{CuO}+\mathrm{CH} 3 \mathrm{COONa} \rightarrow \mathrm{CuSO} 4+\mathrm{H} 2 \mathrm{O}
$$

Reaksi antara asam sulfat dengan logam biasanya akan menghasilkan hydrogen $^{(173)}$,hal ini karena asam pekat panas berperan sebagai oksidator.sehingga ketika asam panas bereaksi dengan seng,timah,dan tembaga, akan menghasilkan garam,air dan sulfur dioksida.seperti:

$$
\mathrm{Fe}+\mathrm{H} 2 \mathrm{SO} 4 \rightarrow \mathrm{H} 2+\mathrm{FeSO} 4
$$

Asam sulfat mudah larut ${ }^{(241)}$ dalam air dingin. Sulfat larut dalam air dengan pembebasan banyak panas. Larut dalam etil alkohol.asam sulfat berbau, namun memiliki bau tersedak ketika panas dan memiliki rasa asam.

Asam sulfat juga digunakan sebagai agen sulfonasi, sebagai dehydrator dan oksidator ${ }^{(157,158,159,160)}$.

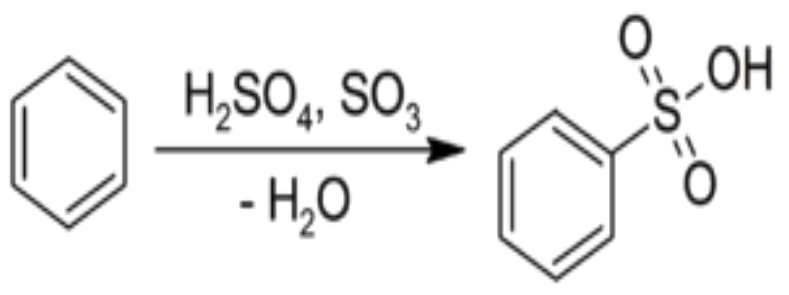

Gambar 3. Sulfonasi dari molekul $\mathrm{H}_{2} \mathrm{SO}_{4}$

\subsection{Bentuk Molekul}

Asam sulfat mempunyai rumus kimia $\mathrm{H} 2 \mathrm{SO} 4$ terdiri dari atom $\mathrm{H}^{(202)}, \mathrm{S}$, dan O. Hydrogen golongan IA yang mempunyai 1 elektron ${ }^{(124)}$ valensi.sulfur termasuk golongan VIA yang memiliki electron valensi 6 dan oksigen adalah golongan VIA yang mempunyai electron valensi 6.sehingga bentuk molekul tetrahedral $^{(171)}$ pada asam sulfat.

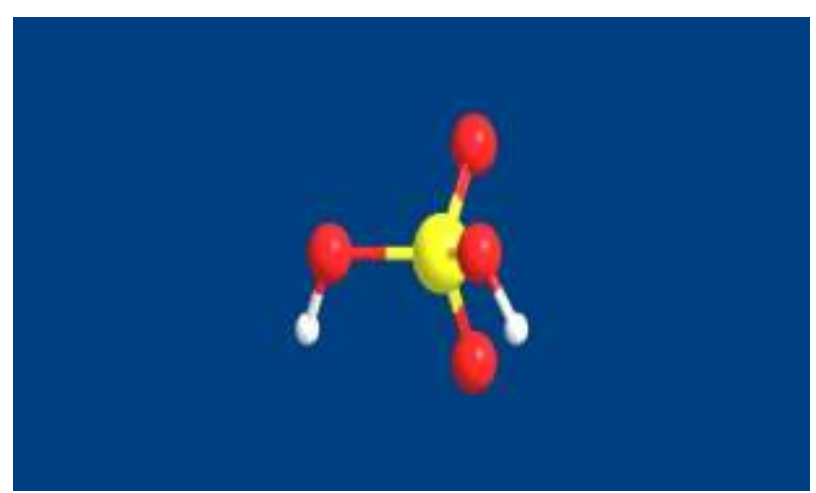

Gambar 4. Asam sulfat 3D( N. L. Allinger, J. Comput. Chem.1993, 14, 755-68) 


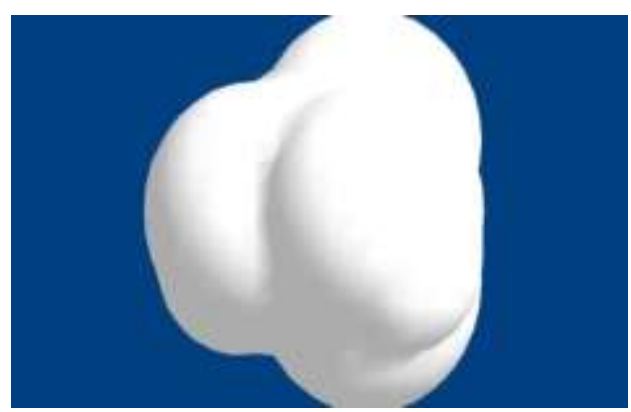

(a)

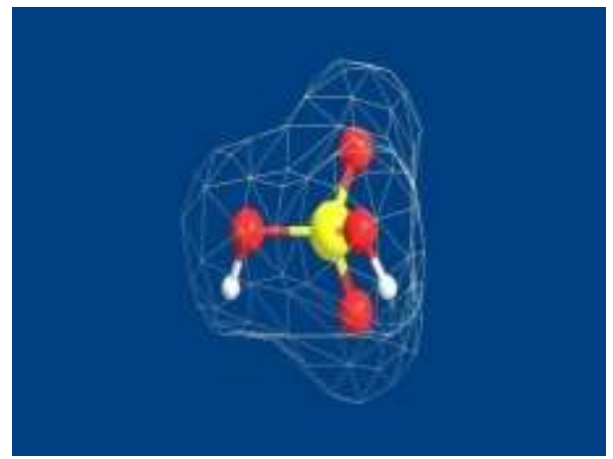

(b)

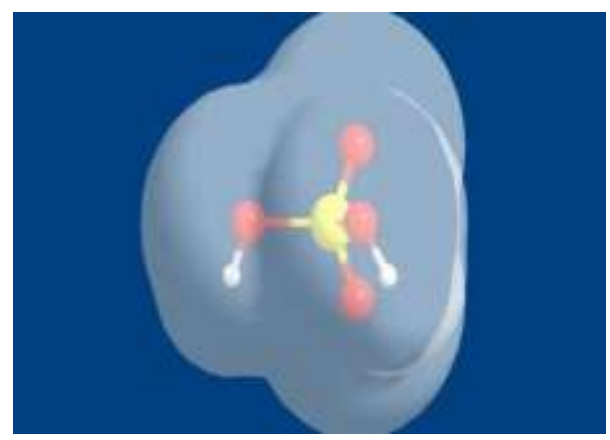

(c)

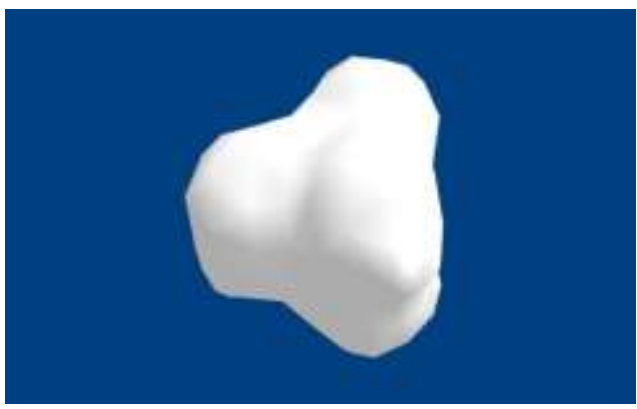

(d)

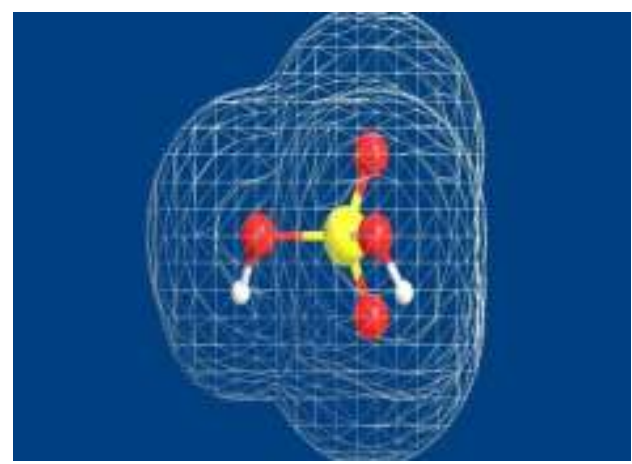

(e)

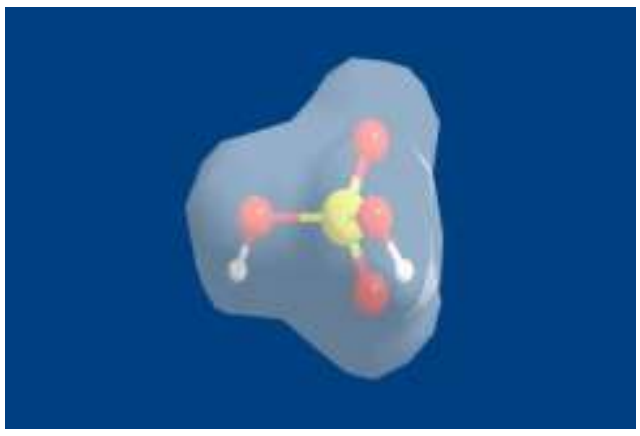

(d)

Gambar 5. Analisis 3D surface $\mathrm{H}_{2} \mathrm{SO}_{4}$. (a),(b) dan (c) solvent accessible surface solid, wire mesh dan translucent. (d), (e) dan (f) Connolly molecular surface solid, wire meshdan transculent.( N. L. Allinger, J. Comput. Chem.1993, 14, 755-68)

\section{Output MM2 Minimization, Dynammics dan Properties} ----------MM2 Minimization------------

MM2 Job Type

Menu Name : Minimize Energy

Current Options Tab

$: 4$

Display Iterations

Pi Bond Orders

Steric Energy Summary

Minimum RMS Gradient: 0,10000 
$\begin{array}{ll}\text { Step Interval } & : 2.00000 \\ \text { Frame Interval } & : 10 \\ \text { Terminate Steps } & : 10000 \\ \text { Heating Rate } & : 1.00000 \\ \text { Target Temperature } & : 300\end{array}$

----------MM2 Dynamics----------

MM2 Job Type

Menu Name : Minimize energy

Current options tab : 2

Display Iterations

Record iterations

Copy Measurements

Pi bond Orders

Steric energy summary

Minimum RMS gradient $\quad: 0,10000$

Move only selection

Step interval $\quad: 2.00000$

Frame interval $\quad: 10$

Terminate steps $\quad: 10000$

Heating rate $\quad: 1.00000$

Target temperature $\quad: 300$

\section{-------MM2 Properties---------}

MM2 Job Type

Menu Name : compute properties

Current options tab : 3

Display iterations

Pi bond orders

Steric energy summary

Minimum RMS gradient $\quad: 0,10000$

Step interval $\quad: 2.00000$

Frame interval $\quad: 10$

Terminate steps $\quad: 10000$

Heating rate $: 1.00000$

Target temperature $: 300$

\section{Output MOPAC Minimization, dan Properties} -------MOPAC Miinimization--------

MOPAC Job Type

Menu Name : minimize energy

Current options tab : 1

Display iterations

Heat of formation

Gradient norm

Additional keywords:

Job type : minimize energy

Minimum RMS gradient : 0.09999 
Method

Wave function

: AMI

Charge scheme

$: 1$

Dielectric

$: 1$

: 78,50120

--------MOPAC properties--------

MOPAC job type

Menu name

: compute properties

Current options tab

$: 3$

Display iterations

Heat formation

Gradien norm

Dipole

Charges

Additional keywords

Job type : compute properties

Minimum RMS gradient : 0,09999

Method

: AMI

Wave function $: 1$

Charge scheme $\quad: 1$

Dielectric : 78,50120

\begin{tabular}{lc}
\hline Atom & actual \\
\hline $\mathrm{S}(1)-\mathrm{O}(2)$ & 1.428 \\
$\mathrm{~S}(1)-\mathrm{O}(3)$ & 1.428 \\
$\mathrm{~S}(1)-\mathrm{O}(4)$ & 1.660 \\
$\mathrm{~S}(1)-\mathrm{O}(6)$ & 1.660 \\
$\mathrm{O}(4)-\mathrm{H}(5)$ & 0.992 \\
$\mathrm{O}(6)-\mathrm{H}(7)$ & 0.992 \\
$\mathrm{O}(2)-\mathrm{S}(1)-\mathrm{O}(3)$ & 109.500 \\
$\mathrm{O}(2)-\mathrm{S}(1)-\mathrm{O}(4)$ & 109.500 \\
$\mathrm{O}(2)-\mathrm{S}(1)-\mathrm{O}(6)$ & 109.500 \\
$\mathrm{O}(3)-\mathrm{S}(1)-\mathrm{O}(4)$ & 109.500 \\
$\mathrm{O}(3)-\mathrm{S}(1)-\mathrm{O}(6)$ & 109.327 \\
$\mathrm{O}(4)-\mathrm{S}(1)-\mathrm{O}(6)$ & 109.500 \\
$\mathrm{~S}(1)-\mathrm{O}(4)-\mathrm{H}(5)$ & 109.500 \\
$\mathrm{~S}(1)-\mathrm{O}(6)-\mathrm{H}(7)$ & 109.500 \\
\hline
\end{tabular}




$$
\begin{array}{cc}
\mathrm{O}(2)-\mathrm{S}(1)-\mathrm{O}(4)-\mathrm{H}(5) & 120.000 \\
\mathrm{O}(3)-\mathrm{S}(1)-\mathrm{O}(4)-\mathrm{H}(5) & -0.071 \\
\mathrm{O}(6)-\mathrm{S}(1)-\mathrm{O}(4)-\mathrm{H}(5) & -119.929 \\
\mathrm{O}(2)-\mathrm{S}(1)-\mathrm{O}(6)-\mathrm{H}(7) & -119.000 \\
\mathrm{O}(3)-\mathrm{S}(1)-\mathrm{O}(6)-\mathrm{H}(7) & -0.035 \\
\mathrm{O}(4)-\mathrm{S}(1)-\mathrm{O}(6)-\mathrm{H}(7) & 119.929
\end{array}
$$

Table 1. jarak antara atom pada molekul $\mathrm{H} 2 \mathrm{SO} 4$ dengan menggunakan measurements (raber, D.J., et. Al. JOC, 1989,54,5032-5035)

\subsection{Sintesis Asam Sulfat}

Sintesis ${ }^{(229,144)}$ asam sulfat dilakukan dengan bermacam-macam proses ${ }^{(227)}$ yaitu:

\subsection{1. pembuatan asam sulfat dengan proses kamar timbale}

Pada proses ini campuran gas SO2 dan udara dialirkan kr dalam bilik yang dilapisis timbel dengan menggunakan katalis NO dan NO2. Pada campuran gas-gas ini dialirkan uap air ${ }^{(145)}$, reaksi nya sebagai berikut :

$$
\begin{aligned}
& 2 \mathrm{SO}_{2}+\mathrm{O}_{2}+\mathrm{NO}+\mathrm{NO}_{2}+\mathrm{H}_{2} \mathrm{O} \rightarrow 2 \mathrm{HNOSO}_{4} \text { (asam nitrosil) } \\
& 2 \mathrm{HNOSO}_{4}+\mathrm{H}_{2} \mathrm{O} \rightarrow 2 \mathrm{H} 2 \mathrm{SO} 4+\mathrm{NO}+\mathrm{NO}_{2}
\end{aligned}
$$

Proses kamar timbale ini, merupakan cara pembuatan ${ }^{(203,204)}$ asam sulfat pertama kali dilakukan dan hanya menghasilkan asam sulfat dengan kadar $80 \%$ berat,sedangkan saat ini penggunaan asam sulfat dalam industri adalah kadar yang sangat tinggi yaitu 98\%. Karena itu, proses ini tidak memungkinkan untuk mendapatkan kadar $98 \%$.

\subsection{2. pembuatan dengan proses kontak}

Melalui proses kontak, asam sulfat diproduksi dari belerang, oksigen dan air. Pada tahap pertama, belerang dipanaskan untuk mendapatkan sulfur dioksida:

$\mathrm{S}(\mathrm{s})+\mathrm{O}_{2}(\mathrm{~g}) \rightarrow \mathrm{SO}_{2}(\mathrm{~g})$

Sulfur dioksida kemudian dioksidasi menggunakan oksigen dengan adanya katalis vanadium oksida:

$$
2 \mathrm{SO}_{2}+\mathrm{O}_{2}(\mathrm{~g}) \rightarrow 2 \mathrm{SO}_{3}(\mathrm{~g})
$$

Sulfur trioksida diserap kedalam $97-98 \%$ asam sulfat menjadi oleum $\left(\mathrm{H}_{2} \mathrm{~S}_{2} \mathrm{O}_{7}\right)$, yang dikenal sebagai asam sulfat berasap. Kemudian oleum diencerkan ke dalam air menjadi asam sulfat pekat.

$$
\begin{aligned}
& \mathrm{H}_{2} \mathrm{SO}_{4}(\mathrm{l})+\mathrm{SO}_{3} \rightarrow \mathrm{H}_{2} \mathrm{~S}_{2} \mathrm{O}_{7}(\mathrm{l}) \\
& \mathrm{H}_{2} \mathrm{~S}_{2} \mathrm{O}_{7}(\mathrm{l})+\mathrm{H}_{2} \mathrm{O}(\mathrm{l}) \rightarrow 2 \mathrm{H}_{2} \mathrm{SO}_{4}(\mathrm{l})
\end{aligned}
$$


Karena reaksi sulfur trioksida dengan air bersifat eksotermik, pelarutan SO3 kedalam air tidak praktis.reaksi ini akan membentuk aerosol korosif yang akan sulit dipisahkan.

$\mathrm{SO}_{3}(\mathrm{~g})+\mathrm{H}_{2} \mathrm{O}(\mathrm{l}) \rightarrow \mathrm{H}_{2} \mathrm{SO}_{4}(\mathrm{l})$

\subsection{Karakteristik Atom Penyusun dan Ion}

\subsubsection{Hidrogen}

Hydrogen adalah unsure kimia pada table periodic yang memiliki symbol $\mathrm{H}$ dan nomor atom 1. Pada suhu dan tekanan standard, hydrogen tidak berwarna, tidak berbau, bersifat non-logam, bervalensi tunggal, dan merupakan gasdiatomik yang sangat mudah terbakar.

Table 2. sifat fisika dan kimia unsure $\mathrm{H}$

\begin{tabular}{cc}
\hline Sifat fisika dan kimia & Data \\
\hline Warna & Tak berwarna \\
Fase & Gas \\
Titik lebur & $13,99 \mathrm{k}$ \\
Titik didih & $20271 \mathrm{k}$ \\
Kepadatan & $0,08988 \mathrm{~g} / \mathrm{l}$ \\
Titik tripel & $13,8033 \mathrm{k}$ \\
Titik kritis & $32,938 \mathrm{k}$ \\
Kalor peleburan & $0,117 \mathrm{kj} / \mathrm{mol}$ \\
Kalor penguapan & $0,904 \mathrm{kj} / \mathrm{mol}$ \\
Kapasitas kalor molar & $28,836 \mathrm{j} /(\mathrm{mol} . \mathrm{k})$ \\
\hline
\end{tabular}

\subsubsection{Sulfur (Belerang)}

Sulfur atau belerang merupakan salah satu unsure kimia dalam table periodik memiliki nomor atom 16 dan memiliki lambing S. Sulfur merupakan unsure non logam yang tidak memiliki rasa. Belerang dalam bentuk aslinya berbentuk padatan kristalin kuning. Dialam bebas, belerang ditemukan sebagai unsure murni maupun sebagai mineral-mineral sulfida dan sulfat. Belerang adalah unsure yang ditemukan dalam dua buah asam amino. Contoh penggunaan belerang umumnya adalah dalam pupuk, bubuk mesiu, korek api, insektisida dan fungisida.

Sulfur memiliki beberapa sifat yaitu:

Table 3. Sifat Fisika dan Kimia Unsur S

\begin{tabular}{cc}
\hline Sifat Fisika dan Kimia & Data \\
\hline Penampilan & Padatan kristalin kuning \\
Rasa & Tidak berasa \\
Massa atom $(\mathrm{gr} / \mathrm{mol})$ & 32,065 \\
Jari-jari atom & $102 \mathrm{pm}$ \\
Jari-jari kovalen & $105 \pm 5 \mathrm{pm}$ \\
Jari-jari van der waals & $180 \mathrm{pm}$ \\
Jari-jari ion & $0,29 \mathrm{~A}(-6)$ \\
& $1,84 \mathrm{~A}(+2)$ \\
Kepadatan $\left(\mathrm{gr} / \mathrm{cc}^{3}\right)$ & 1,96 \\
Titik lebur & $115,21^{\circ} \mathrm{C}$ \\
Titik didih & $444,6^{0} \mathrm{C}$ \\
\hline
\end{tabular}




\begin{tabular}{cc}
\hline Elektronegativitas & $2,58 \mathrm{pauling}$ \\
Potensial ionisasi & $999,6 \mathrm{kj} / \mathrm{mol}$ \\
Kalor peleburan & $($ mono) $1,727 \mathrm{kj} / \mathrm{mol}$ \\
Kalor penguapan & $(\mathrm{mono}) 45 \mathrm{kj} / \mathrm{mol}$ \\
Kapasitas kalor molar & $22,75 \mathrm{j} /(\mathrm{mol} . \mathrm{k})$ \\
Struktur kristal & ortorombus \\
\hline
\end{tabular}

\subsection{3 oksigen}

Oksigen adalah salah satu unsure kimia dalam system periodic yang bernomor atom 8 dan berlambang O. Oksigen mudah bereaksi dengan hamper semua unsure lainnya (terutama menjadi oksida). Pada keadaan standard, dua atom unsure oksigen berikatan menjadi senyawa dioksigen dengan rumus $\mathrm{O}_{2}$ yang tidak berwarna, tidak berasa, dan tidak berbau.

Table 4. Sifat Fisika dan Kimia unsure O

\begin{tabular}{cc}
\hline Sifat fisika dan kimia & Data \\
\hline Penampilan & Gas \\
Bau & Tidak berbau \\
Massa atom $(\mathrm{gr} / \mathrm{mol})$ & 15,9994 \\
Jari-jari atom & $74 \mathrm{pm}$ \\
Jari-jari kovalen & $66 \pm 2 \mathrm{pm}$ \\
Jari-jari van der waals & $152 \mathrm{pm}$ \\
Jari-jari ion & $1,40 \mathrm{~A}(-2)$ \\
Kepadatan $($ gr/cc $)$ & 1,15 \\
Titik lebur & $-218,35^{\circ} \mathrm{C}$ \\
Titik didih & $-182,95^{\circ} \mathrm{C}$ \\
Elektronegativitas & $3,44 \mathrm{pauling}$ \\
Potensial ionisasi & $1313,9 \mathrm{kj} / \mathrm{mol}$ \\
Kalor peleburan & $\left(\mathrm{O}_{2}\right) 0,444 \mathrm{kj} / \mathrm{mol}$ \\
Kalor penguapan & $\left(\mathrm{O}_{2}\right) 6,82 \mathrm{kj} / \mathrm{mol}$ \\
Kapasitas kalor molar & $\left(\mathrm{O}_{2}\right) 29,378 \mathrm{~J} /(\mathrm{mol} . \mathrm{k})$ \\
Struktur Kristal & $\mathrm{kubus}$ \\
\hline
\end{tabular}

\subsection{4 sulfat}<smiles>O=S(=O)([O-])[O-]</smiles>

sulfate

Caution: A net charge appears to be present

Gambar 2. Anion sulfat (chemoffice 2D version 8.0, perkinelmer informatics. Inc, 2015) 
Ion sulfat merupakan anion poliatomik dengan rumus empiris $\mathrm{SO}_{4}{ }^{2-}$. Garam sulfat memiliki beragam aplikasi. Contohnya, asam sulfat digunakan dalam pembuatan deterjen. Seringkali kombinasi senyawa sulfat menghasilkan senyawa ionic, meskipun sulfat dapat telibat dalam ikatan kovalen dengan sebagian besar unsure.banyak garam sulfat larut dalam air. Namun, kalsium sulfat, stronsium sulfat dan barium sulfat sangat sulit larut dalam air.

\subsection{5 karakterisasi asam sulfat}

Asam sulfat murni yang tidak diencerkan tidak dapat ditemukan secara alami di bumi karena sifatnya yang higroskopis. Walaupun demikian, asam sulfat merupakan komponen utama hujan asam, yang terjadi karena oksidasi sulfur dioksida diatmosfer dengan keberadaan air.

Stretch-bend : $-0,5337$

Torsiob: $\quad 39,0831$

Non-1,4 VDW: - 0,2790

1,4 VDW : $-4,5627$

Dipole/dipole: 16,6640

MM2 Calculation completed successfully

-----------MM2 Minimization-------------

Warning: Some parameters are guessed (Quality $=1)$.

\begin{tabular}{|c|c|c|c|c|c|c|}
\hline Iteration & 1 Steric Energy & 386.050 & RMS Gradient & 210.174 & 4 RMS Move & 0.0000 \\
\hline Iteration & 2 Steric Energy & 268.128 & RMS Gradient & 85.530 & RMS Move & 0.0408 \\
\hline Iteration & 3 Steric Energy & 239.950 & RMS Gradient & 59.457 & RMS Move & 0.0231 \\
\hline Iteration & 4 Steric Energy & 220.911 & RMS Gradient & 23.831 & RMS Move & 0.0107 \\
\hline Iteration & 5 Steric Energy & 216.149 & RMS Gradient & 28.895 & RMS Move & 0.0114 \\
\hline Iteration & 6 Steric Energy & 211.050 & RMS Gradient & 16.706 & RMS Move & 0.0146 \\
\hline Iteration & 7 Steric Energy & 209.883 & RMS Gradient & 14.202 & RMS Move & 0.0048 \\
\hline Iteration & 8 Steric Energy & 208.727 & RMS Gradient & 12.961 & RMS Move & 0.0053 \\
\hline Iteration & 9 Steric Energy & 207.104 & RMS Gradient & 14.226 & RMS Move & 0.0110 \\
\hline Iteration & 10 Steric Energy & 206.084 & RMS Gradient & 9.314 & RMS Move & 0.0041 \\
\hline Iteration & 11 Steric Energy & 205.036 & RMS Gradient & $\mathrm{t} \quad 11.000$ & RMS Move & 0.0075 \\
\hline Iteration & 12 Steric Energy & 203.350 & RMS Gradient & 10.215 & RMS Move & 0.0173 \\
\hline Iteration & 13 Steric Energy & 202.332 & RMS Gradient & 8.568 & RMS Move & 0.0061 \\
\hline Iteration & 14 Steric Energy & 201.112 & RMS Gradient & t 11.041 & I RMS Move & 0.0111 \\
\hline Iteration & 15 Steric Energy & 200.257 & RMS Gradient & 6.999 & RMS Move & 0.0062 \\
\hline
\end{tabular}




\begin{tabular}{|c|c|c|c|c|c|c|}
\hline Iteration & 16 Steric Energy & 199.447 & RMS Gradient & 8.972 & RMS Move & 0.0085 \\
\hline Iteration & 17 Steric Energy & 198.937 & RMS Gradient & 6.656 & RMS Move & 0.0051 \\
\hline Iteration & 18 Steric Energy & 198.402 & RMS Gradient & 8.946 & RMS Move & 0.0062 \\
\hline Iteration & 19 Steric Energy & 197.595 & RMS Gradient & 8.192 & RMS Move & 0.0118 \\
\hline Iteration & 20 Steric Energy & 197.161 & RMS Gradient & 5.734 & RMS Move & 0.0037 \\
\hline Iteration & 21 Steric Energy & 196.837 & RMS Gradient & 3.548 & RMS Move & 0.0022 \\
\hline Iteration & 22 Steric Energy & 196.608 & RMS Gradient & 3.117 & RMS Move & 0.0023 \\
\hline Iteration & 23 Steric Energy & 196.437 & RMS Gradient & 1.962 & RMS Move & 0.0021 \\
\hline Iteration & 24 Steric Energy & 196.109 & RMS Gradient & 6.796 & RMS Move & 0.0099 \\
\hline Iteration & 25 Steric Energy & 195.623 & RMS Gradient & 8.000 & RMS Move & 0.0165 \\
\hline
\end{tabular}

\section{5 konduktivitas}

asam sulfat memiliki konduktivitas yang tinggi. Hal ini diakibatkan oleh disosiasi yang disebabkan oleh swa-protonasi yang disebut sebagai autopirolisis.

$2 \mathrm{H}_{2} \mathrm{SO}_{4} \rightarrow \mathrm{H}_{3} \mathrm{SO}+4+\mathrm{HSO}-4$

Konstanta kesetimbangan autopirolisisnya adalah

$$
\mathrm{K}_{\mathrm{ap}}\left(25^{\circ} \mathrm{C}\right)=\left[\mathrm{H}_{3} \mathrm{SO}+4\right][\mathrm{HSO}-4]=2,7 \times 10^{-4} \text {. }
$$

Nilai konstanta kesetimbangan autopirolisis asam sulfat 10 triliun kali lebih kecil dibandingkan dengan konstanta kesetimbangan air, $\mathrm{Kw}=10^{-14}$.

Meskipun asam sulfat memiliki viskositas yang cukup tinggi, konduktivitas efektifion $\mathrm{H}_{3} \mathrm{SO}+4$ dan $\mathrm{HSO}-4$ tinggi karena mekanisme ulang alik proton intra molekul, menjadikan asam sulfat sebagai konduktor ${ }^{(174)}$ yang baik. asam sulfat juga adalah pelarut yang baik untuk rekasi kimia.

Kesetimbangan kimiawi asam sulfat sebenarnya lebih rumit.100\% $\mathrm{H}_{2} \mathrm{SO}_{4}$ mengandung beragam spesi dalam kesetimbangan yaitu: $\mathrm{HSO}-4(15,0), \mathrm{H}_{3} \mathrm{SO}+4$ $(11,3), \mathrm{H}_{3} \mathrm{O}^{+}(8,0), \mathrm{HS}_{2} \mathrm{O}-7(4,4), \mathrm{H}_{2} \mathrm{~S}_{2} \mathrm{O}_{7}(3,6), \mathrm{H}_{2} \mathrm{O}(0,1)$.

Konduktivitas digunakan untuk mengukur daya hantar larutan atau cairan elektrolit. Besarnya konduktivitas ditentukan oleh konsentrasi elektrolit.energi listrik dapat ditransfer melalui hantaran yang bermuatan listrik pembawa muatan dapat berupa elektron seperti logam,dapat digunakan ion ${ }^{(205)}$ positif dan ion negatif seperti dalam larutan elektrolit dan lelehan garam. Konduktivitas molar, sehingga secara matematis dirumuskan :

$$
\Delta \mathrm{m}=\mathrm{k} / \mathrm{C}
$$

Jika satuan volume yang digunakan adalah $\mathrm{cm}^{3}$ maka persamaan yang menjadi $\Delta \mathrm{m}=1000 \mathrm{k} / \mathrm{C}$ 


\begin{tabular}{|c|c|c|c|c|c|}
\hline $\mathrm{NO}$ & konsentra & $\mathrm{I}(\mathrm{Ma})$ & $\mathrm{V}$ (Volt) & Hambatan $(\Omega)$ & $\begin{array}{l}\text { Daya } \\
\text { hantar } \\
\text { listrik }\left(\Omega^{-1}\right)\end{array}$ \\
\hline 1 & $0,10 \mathrm{M}$ & 0,39 & 2,0 & 5128,20 & $1,95 \times 10^{-4}$ \\
\hline 2 & $0,15 \mathrm{M}$ & 0,47 & 2,0 & 4255,32 & $2,35 \times 10^{-4}$ \\
\hline 3 & $0,20 \mathrm{M}$ & 0,52 & 2,0 & 3846,15 & $2,60 \times 10^{-4}$ \\
\hline 4 & $0,25 \mathrm{M}$ & 0,57 & 2,0 & 3508,77 & $2,85 \times 10^{-4}$ \\
\hline 5 & $0,30 \mathrm{M}$ & 0,62 & 2,0 & 3225,80 & $3,10 \times 10^{-4}$ \\
\hline
\end{tabular}

Dari data diatas diperoleh grafik sebagai berikut

Grafik 1. Konduktivitas senyawa asam sulfat

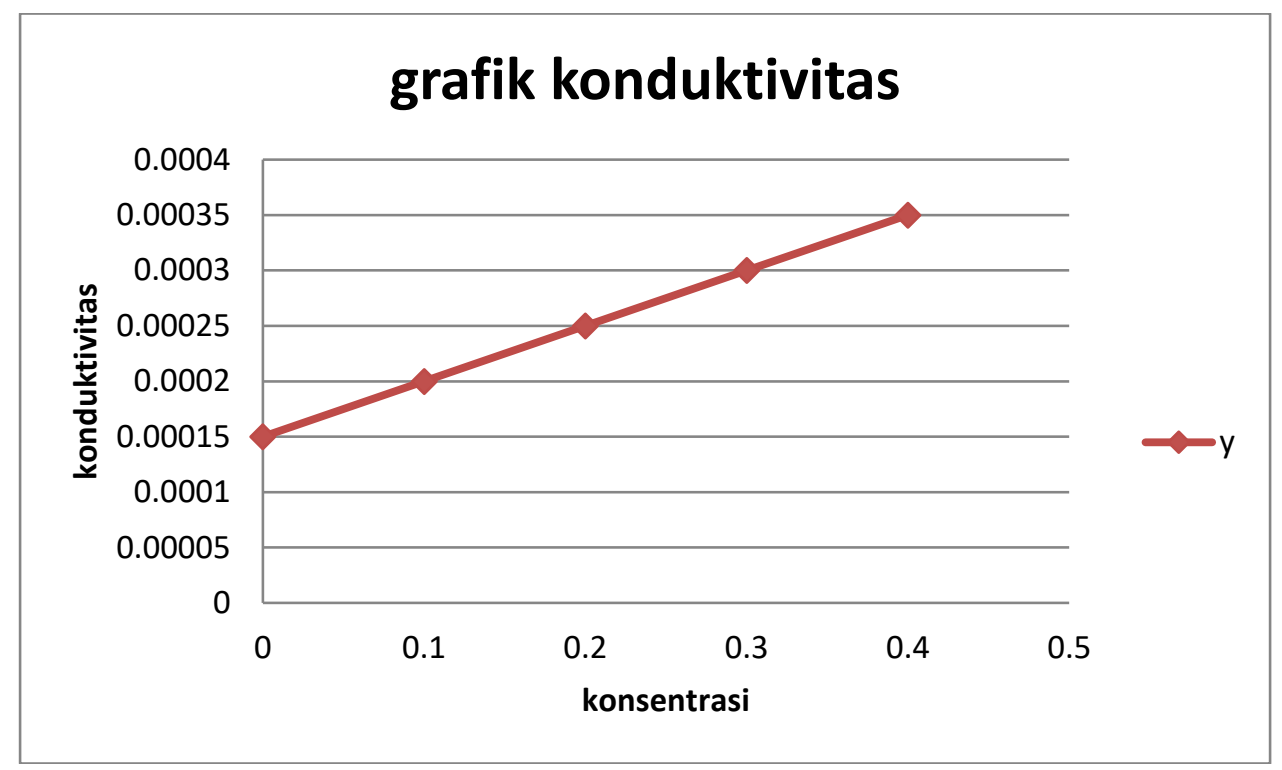

\subsection{Termokimia}

Termokimia adalah cabang kimia yang berhubungan dengan hubungan timbale balik panas dengan reaksi kimia atau dengan perubahan keadaan fisika. Secara umum, termokimia ialah penerapan termodinamika kimia. Termokimia larutan asam sulfat dibagi menjadi dua yaitu entropi molar standard dan entalpi standard.

Entropi molar standard adalah kandungan entropi dalam satu mol zat pada keadaan standard.entropi molar standard biasanya disimbolkan dengan $\mathrm{S}^{0}$ dan satuannya joule per mol Kelvin. Unsure dalam keadaan standard memiliki niai bukan nol yang pasti $S$ pada suhu ruangan.

Perubahan entalpi pembentukan standard atau pembentukan panas standard dari suatu senyawa ialah besarnya perubahan entalpi dari 1 mol senyawa dari elemen-elemenya dalam keadaan standard.lambangnya $\Delta \mathrm{Hf}$. Perubahan entalpi pembentukan standard diukur dalam energy persatuan unit substansi. Satuan yang sering dipakai adalah kilojoule permol,tetapi juga dapat diukur dalam satuan kalori permol,joule permol, atau kilokalori per mol.

Energy bebas gibbs pembentukan standard pada suatu senyawa adalah perubahan energy bebas gibbs yang menyertai pembentukan 1 mol zat tersebut dari unsur penyusunnya, pada keadaan standart simbolnya adalah $\Delta_{\mathrm{f}} \mathrm{G}$, semuanya 
unsure dalam keadaan standarnya memiliki energi bebas gibbs pembentukan standard sama dengan nol.

$\Delta_{\mathrm{f}} \mathrm{G}=\Delta_{\mathrm{f}} \mathrm{G}^{0}+\mathrm{RT} \ln \mathrm{Q}_{1} ; \mathrm{Q}_{\mathrm{f}}$ adalah hasil bagi reaksi.

\subsection{Mobilitas Ion}

Mobilitas ion mmerupakan kecepatan ion pada beda potensial antara kedua elektroda atau bias dibilang perbandingan antara laju dan kuat medan.Mobilitas ion dapat dihitung dengan pengukuran ${ }^{(126)}$ sebenarnya antara jarak yang ditempuh setiap ion dalam waktu tertentu dengan metode atas bergerak.

$$
\begin{aligned}
& U=\frac{x}{t\left(\frac{d E}{d x}\right)} \\
& \mathrm{x}=\operatorname{jarak}(\mathrm{m}) \\
& \mathrm{t}=\text { waktu }(\mathrm{dt}) \\
& \left(\frac{d E}{d x}\right)=\text { kekuatan medan }\left(\text { volt } . \mathrm{m}^{-1}\right) \\
& E=\frac{d E}{d x}=\frac{I}{A L_{s}} \\
& \text { Maka } U=\frac{\lambda_{m}}{{ }_{z} F} \\
& \mathrm{Z}=\text { valensi kation } \\
& \mathrm{F}=\text { Faraday }
\end{aligned}
$$

\subsection{Kecepatan hanyut}

Didalam konduktor-konduktor zat,cairan,ataupun padat suatu partikel yang mengalami aktivitas ${ }^{(134,108,109)}$ tumbukan secara berulang-ulang akan menyebabkan kehilangan energy dan perubahan gerak secara acak.untuk menahan partikel bermuatan agar kecepatan rata-rata tetap digunakan kecepatan hanyut.kecepatan hanyut mempunyai arah sama dengan medan listrikdan ubungan keduanya dinyatakan dalam suatu konstanta yang disebut mobilitas.Gaya yang disebabkan medan listrik.

$$
F=Z e . E
$$


Jika dua elektroda yang terpisah dengan jarak 1 berada pada selisih potensial $(\Delta \phi)$, maka ion dalam larutan diantara kedua elektroda tersebut, mengalami medan listrik (E) sebesar:

$$
E=\frac{\Delta \phi}{l}
$$

Untuk ion ze (muatan ion) mengalami gaya sebesar :

$$
F=z e E=\frac{z e \Delta \phi}{l}
$$

Sedangkan gaya perlambatan (F'), sedangkan gaya gesek (f) maka :

$$
F^{\prime}=f s \quad \mathrm{f}=6 \pi \eta a
$$

Kedua gaya ini bekerja dalam arah yang berlawanan dan ion mencapai kecepatan akhir, yaitu kecepatan hanyut ion (s), jika gaya mempercepat F diimbangi oleh gaya perlambatan $F^{\prime}$. Gaya neto menjadi nol $\left(F=F^{\prime}\right)^{(195-200)}$ jika :

$$
s=\frac{z e E}{f}
$$

\section{9 viskositas Kinematik}

Konsep dasar viskositas kinematik adalah perkembangan dari penggunaan cairan untuk menghasilkan aliran melalui suatu tabung kapiler. Koefisien viskositas absolute, apabila dibagi oleh kerapatan fluidanya disebut viskositas kinematik. Dalam sistem metrik satuan viskositas disebut Stoke dan mempunyai satuan centimetre kuadrat per detik. Biasanya didapatkan satuan pembanding yang lebih kecil yaitu centistoke dan besarnya sama dengan seperseratus stoke. Apabila dikonversikan antara viskositas absolut dan kinematik didapatkan perbandingan :

$$
\begin{array}{r}
\text { Viskositas kinematik }(V k)=\frac{\text { Viskositas Absolut }(\mu)}{\text { Kerapatan }(\rho)} \\
\text { Viskositas khinematik(vk) } \frac{\text { Dyne.derik } / \mathrm{cm} 3}{\text { Dyne.detik } 2-\mathrm{cm} 4}
\end{array}
$$

Dinyatakan sebagai satuan Stoke (S) setelah Stoke menemukan dasar tentang dinamika fluida. Satuan Stoke adalah terlalu besar untuk jenis fluida yang digunakan dalam hidrolika industry, dan viskositas kinematik yang dinyatakan dalam satuan SI diberikan dalam skala yang lebih kecil yaitu centistoke. 


\subsection{0 energy stability}

Energy stabilitas yaitu energy dalam keadaan termodinamika pada suatu molekul yang mengalami kesetimbangan kimia dengan lingkungannya. Berikut optimasi energy stability dari molekul asam sulfat yang di tinjau menggunakan chem. Ultra 3D:

MM2 Calculation completed successfully

MM2 Dynamics

Warning: Some parameters are guessed (Quality $=1)$.

\begin{tabular}{rrrrrr}
\hline Iteration Time & Total Energy & Potential Energy & Temperature \\
\hline 1 & 0.002 & $187.673 \pm 0.000$ & $187.673 \pm 0.000$ & $0.00 \pm 0.00$ \\
2 & 0.004 & $187.749 \pm 0.000$ & $187.725 \pm 0.000$ & $0.54 \pm 0.00$ \\
3 & 0.006 & $187.796 \pm 0.000$ & $187.764 \pm 0.000$ & $0.71 \pm 0.00$ \\
4 & 0.008 & $187.940 \pm 0.000$ & $187.870 \pm 0.000$ & $1.55 \pm 0.00$ \\
5 & 0.010 & $188.083 \pm 0.000$ & $188.010 \pm 0.000$ & $1.64 \pm 0.00$ \\
6 & 0.012 & $188.232 \pm 0.000$ & $188.086 \pm 0.000$ & $3.27 \pm 0.00$ \\
7 & 0.014 & $188.363 \pm 0.000$ & $188.171 \pm 0.000$ & $4.29 \pm 0.00$ \\
8 & 0.016 & $188.618 \pm 0.000$ & $188.445 \pm 0.000$ & $3.89 \pm 0.00$ \\
9 & 0.018 & $188.794 \pm 0.000$ & $188.560 \pm 0.000$ & $5.25 \pm 0.00$ \\
10 & 0.020 & $189.353 \pm 0.000$ & $189.034 \pm 0.000$ & $7.14 \pm 0.00$ \\
11 & 0.022 & $189.482 \pm 0.000$ & $189.104 \pm 0.000$ & $8.45 \pm 0.00$ \\
12 & 0.024 & $189.958 \pm 0.000$ & $189.441 \pm 0.000$ & $11.56 \pm 0.00$ \\
13 & 0.026 & $189.656 \pm 0.000$ & $189.126 \pm 0.000$ & $11.86 \pm 0.00$ \\
14 & 0.028 & $189.821 \pm 0.000$ & $189.325 \pm 0.000$ & $11.08 \pm 0.00$ \\
15 & 0.030 & $189.600 \pm 0.000$ & $189.071 \pm 0.000$ & $11.83 \pm 0.00$ \\
16 & 0.032 & $189.856 \pm 0.000$ & $189.341 \pm 0.000$ & $11.51 \pm 0.00$ \\
17 & 0.034 & $189.441 \pm 0.000$ & $188.861 \pm 0.000$ & $12.99 \pm 0.00$ \\
18 & 0.036 & $189.215 \pm 0.000$ & $188.688 \pm 0.000$ & $11.79 \pm 0.00$ \\
19 & 0.038 & $188.915 \pm 0.000$ & $188.533 \pm 0.000$ & $8.54 \pm 0.00$ \\
20 & 0.040 & $188.773 \pm 0.000$ & $188.385 \pm 0.000$ & $8.68 \pm 0.00$ \\
\hline
\end{tabular}

MM2 Calculation completed successfully

MM2 Properties-

Warning: Some parameters are guessed (Quality $=1)$.

Stretch:

0.6738

Bend:

138.0742

Stretch-Bend: $\quad-0.6280$

Torsion: $\quad 38.5599$

Non-1,4 VDW: $\quad-0.2795$ 

1,4 VDW: $\quad-4.5789$
Dipole/Dipole: $\quad 16.5634$
Total Energy: $\quad 188.3849 \mathrm{kcal} / \mathrm{mol}$

The total energy for this frame: $188.385 \mathrm{kcal} / \mathrm{mol}$

Calculation ended

-Calculate MMFF94 Energy and Gradient

The total energy for this frame: $-92.629 \mathrm{kcal} / \mathrm{mol}$

The RMS Gradient is: 66.051

VDW Interaction Radius Eps Quality

$7-21 \quad 1.830 \quad 2.950 \quad 4$

6-21 $\quad 1.830 \quad 1.300 \quad 4$

\subsection{1 kegunaan}

1. Asam sulfat digunakan ${ }^{(230)}$ pada proses pembuatan dan produksi ${ }^{(82,132)}$ deterjen

2. Asam sulfat juga digunakan sebagai larutan elektrolit pada pembuatan batere untuk industri otomotif.

3. Industri pembuatan asam nitrat atau HNO3 juga menggunakan asam kuat yang satu ini.

4. Pada proses penyulingan minyak bumi, asam sulfat digunakan dalam proses penghilangan zat-zat pengotor dari minyak bumi.

5. Proses pembuatan pupuk superfosfat dan amonium sulfat juga menggunakan asam sulfat sebagai bahan bakunya.

6. Asam sulfat digunakan sebagai salah satu reaktan pada proses pembuatan dan produksi ${ }^{(251)}$ bahan peledak, nitrogliserin.

7. Proses pembuatan rayon juga menggunakan asam sulfat. Serat selulosa kayu setelah dicampur dengan tetra amine copper (II) direaksikan dengan asam sulfat untuk menghasilkan serat rayon.

8. Asam kuat yang satu ini juga dipergunakan sebagai bahan pembuat bahan perekat atau lem.

9. Untuk meregenerasi kation resin - pada unit pembuatan air bebas mineral selain biasa menggunakan asam klorida juga dapat digunakan asam sulfat.

10. Di laboratorium analisa, asam sulfat biasa digunakan sebagai salah satu chemical reagent.

11. Asam sulfat digunakan pula pada proses pembuatan bahan pewarna.

12. Pada proses pengolahan logam - besi dan baja - asam sulfat berperan pada proses cleaning (pickling) sebelum logam melalui proses plating dengan seng atau timah. 
13. Pada proses water treatment, asam sulfat dimanfaatkan sebagai bahan kimia untuk pengaturan keasamaan atau $\mathrm{pH}$ adjustment. Penggunaan asam sulfat lebih disukai dibandingkan dengan asam klorida. Karena asam klorida dapat mengakibatkan korosi pada perpipaan atau peralatan yang terbuat dari stainless steel.

\subsection{2 bahaya}

1.bahaya laboratorium

Sifat-sifat asam sulfat yang korosif diperburuk oleh reaksi eksotermiknya dengan air. Luka bakar akibat asam sulfat encer akan dapat mendehidrasi kertas apabila tetesan asam sulfat tersebut dibiarkan dalam waktu lama.

Penanganan pertama yang standard dalam menangani tumpahnya asam sulfat ke kulit adalah dengan membilas kulit tersebut dengan air mengalir sebanyakbanyaknya.pembilasan dilanjutkan selama 10 sampai 15 menit untuk mendinginkan jaringan disekitar luka bakar asam dan untuk menghindari kerusakan sekunder.

2.bahaya industry

Kontak dengan kulit yang menyebabkan luka bakar dan penghirupan aerosol asap. Paparan dengan aerosol asam pada konsentrasi tinggi akan menyebabkan iritasi mata, saluran pernapasan, dan membran mukosa yang parah. Iritasi akan mereda dengan cepat setelah paparan, walaupun terdapat risiko edema paru apabila kerusakan jaringan lebih parah.

\subsection{3 kesimpulan}

Asam sulfat mempunyai rumus kimia $\mathrm{H}_{2} \mathrm{SO}_{4}$, merupakan asam mineral (anorganik) yang kuat dan larut dalam air pada semua perbandingan. Asam sulfat $100 \%$ dapat dibuat namun ia akan melepaskan $\mathrm{SO}_{3}$ pada titik didihnya dan menghasilkan asam 98,3\%. Asam sulfat mempunyai termokimia dalam fase liquid dengan $\Delta \mathrm{H}$ sebesar $-843,99 \mathrm{kj} / \mathrm{mol}, \Delta \mathrm{G}$ sebesar $109,699 \mathrm{kj} / \mathrm{mol}, \mathrm{S}^{0}$ sebesar $156,9 \mathrm{j} / \mathrm{mol} . \mathrm{k}$, dan Cp sebesar 0,418961 kj/k.mol. interaksi yang terjadi pada ion $\mathrm{H}_{2} \mathrm{SO}_{4}$ dapat diperhatikan melalui beberapa parameter, diantaranya adalah konduktivitas, mobilitas, kecepatan hanyut ion nya. Pada konsentrasi rendah yang berpengaruh terhadap konduktivitas $\mathrm{H}_{2} \mathrm{SO}_{4}$ adalah jumlah ion, apabila jumlah ion yang ada dalam suatu larutan semakin banyak, maka akan semakin tinggi konduktivitasnya tetapi setelah mencapai konsentrasi tertentu, semakin banyak ion dalam larutan mobilitas ion yang juga berhubungan dengan kecepatan hanyut dalam larutan akan semakin berkurang sehingga nilai konsuktivitas akan menurun.Konduktivitas dari senyawa asam sulfat semakin meningkat seiring meningkatnya konsentrasi seperti pada grafik 1.energi total yang dibutuhkan $\mathrm{H}_{2} \mathrm{SO}_{4}$ untuk bergerak sebesar 92,629 kcal/mol pada suhu $300 \mathrm{~K}$ dengan RMS gradient yaitu 66,051. asam sulfat juga sangat berbahaya jika terkena dengan alat indra dan juga mempunyai kegunaan dalam bidang industry.

Referensi: 
1. Siffert L, Blaser S, Ottiger P, Leutwyler S. 2018. Transition from Water Wires to Bifurcated HBond Networks in 2-Pyridone.(H2O) $\mathrm{n}, \mathrm{n}=1-4$ Clusters. The journal of physical chemistry. A

2. Al-Oweini R, Bassil BS, Itani M, Emiroglu DB, Kortz U. 2018. The mixed-valent 10manganese(III/IV)-containing 36-tungsto-4-arsenate(V), [Mn(III)6Mn(IV)4O4(OH)12(H2O)12(A-beta-AsW9O34)4](22). Acta crystallographica. Section C, Structural chemistry 74:1390-4

3. Xiong P, Long H, Song J, Wang Y, Li JF, Xu HC. 2018. Electrochemically Enabled Carbohydroxylation of Alkenes with $\mathrm{H} 2 \mathrm{O}$ and Organotrifluoroborates. Journal of the American Chemical Society

4. Zheng L, Zhou B, Jin H, Li T, Liu Y. 2018. Radical-Triggered Tandem Cyclization of 1,6-Enynes with H2O: A Way to Access Strained 1 H-Cyclopropa[ b]naph thalene-2,7-diones. Organic letters

5. $\quad$ Hu CY, Zhou J, Sun CY, Chen MM, Wang XL, Su ZM. 2018. HKUST-1 derived hollow C-Cu2$\mathrm{xS}$ nanotube/g-C3N4 composites for visible-light $\mathrm{CO} 2$ photoreduction with $\mathrm{H} 2 \mathrm{O}$ vapor. Chemistry

6. Wang Y, Zhang Z, Zhang L, Luo Z, Shen J, et al. 2018. Visible-Light Driven Overall Conversion of $\mathrm{CO} 2$ and $\mathrm{H} 2 \mathrm{O}$ to $\mathrm{CH} 4$ and $\mathrm{O} 2$ on 3D-SiC@2D-MoS2 Heterostructure. Journal of the American Chemical Society

7. Li H, Kong X, Jiang L, Liu ZF. 2018. Solvation effects on the N-O and O-H stretching modes in hydrated NO3(-)(H2O)n clusters. Physical chemistry chemical physics : PCCP 20:26918-25

8. Wang X, Shi X, Molokeev MS, Wang Z, Zhu Q, et al. 2018. NaLaW2O7(OH)2(H2O): Crystal Structure and $\mathrm{RE}(3+)$ Luminescence in the Pristine and Annealed Double Tungstates $(\mathrm{RE}=\mathrm{Eu}$, $\mathrm{Tb}, \mathrm{Sm}$, and Dy). Inorganic chemistry 57:13606-17

9. Sajo IE, Bakos LP, Szilagyi IM, Lendvay G, Magyari J, et al. 2018. Unexpected Sequential NH3/H2O Solid/Gas Phase Ligand Exchange and Quasi-Intramolecular Self-Protonation Yield $[\mathrm{NH} 4 \mathrm{Cu}(\mathrm{OH}) \mathrm{MoO} 4]$, a Photocatalyst Misidentified before as $(\mathrm{NH} 4) 2 \mathrm{Cu}(\mathrm{MoO} 4) 2$. Inorganic chemistry 57:13679-92

10. Ouyang XH, Tan FL, Song RJ, Deng W, Li JH. 2018. Palladium-Catalyzed Oxidative [2+ $2+1]$ Annulation of 1,7-Diynes with H2O: Entry to Furo[3,4- c]quinolin-4(5 H)-ones. Organic letters 20:6765-8

11. Nigam S, Majumder C. 2018. Single atom alloy catalyst for SO3 decomposition: enhancement of platinum catalyst's performance by Ag atom embedding. Nanoscale

12. Li H, Zhong J, Vehkamaki H, Kurten T, Wang W, et al. 2018. Self-Catalytic Reaction of SO3 and NH3 To Produce Sulfamic Acid and Its Implication to Atmospheric Particle Formation. Journal of the American Chemical Society 140:11020-8

13. Zhang Z, Zeng Q, Hao R, He H, Yang F, et al. 2019. Combustion behavior, emission characteristics of $\mathrm{SO} 2, \mathrm{SO} 3$ and $\mathrm{NO}$, and in situ control of $\mathrm{SO} 2$ and $\mathrm{NO}$ during the co-combustion of anthracite and dried sawdust sludge. The Science of the total environment 646:716-26

14. Zunino F, Bentz DP, Castro J. 2018. Reducing setting time of blended cement paste containing high-SO3 fly ash (HSFA) using chemical/physical accelerators and by fly ash pre-washing. Cement \& concrete composites $90: 14-26$

15. Lamilla C, Braga D, Castro R, Guimaraes C, L VAdC, et al. 2018. Streptomyces luridus So3.2 from Antarctic soil as a novel producer of compounds with bioemulsification potential. PloS one 13:e0196054

16. Chen S, Zhao Y, Zhang R. 2018. Formation Mechanism of Atmospheric Ammonium Bisulfate: Hydrogen-Bond-Promoted Nearly Barrierless Reactions of SO3 with NH3 and $\mathrm{H} 2 \mathrm{O}$. Chemphyschem : a European journal of chemical physics and physical chemistry 19:967-72

17. Mai TV, Duong MV, Nguyen HT, Huynh LK. 2018. Ab initio kinetics of the HOSO2 + (3)O2 --> $\mathrm{SO} 3+\mathrm{HO} 2$ reaction. Physical chemistry chemical physics : PCCP 20:6677-87 
18. Wang YY, Dash MR, Chung CY, Lee YP. 2018. Detection of transient infrared absorption of $\mathrm{SO} 3$ and 1,3,2-dioxathietane-2,2-dioxide [cyc-(CH2)O(SO2)O] in the reaction $\mathrm{CH} 2 \mathrm{OO}+\mathrm{SO} 2$. The Journal of chemical physics 148:064301

19. Wu Z, Lu B, Feng R, Xu J, Lu Y, et al. 2018. Capture of SO3 isomers in the oxidation of sulfur monoxide with molecular oxygen. Chemical communications 54:1690-3

20. de Souza Bonfim V, Barbosa de Castilho R, Baptista L, Pilling S. 2017. SO3 formation from the $\mathrm{X}$-ray photolysis of SO2 astrophysical ice analogues: FTIR spectroscopy and thermodynamic investigations. Physical chemistry chemical physics : PCCP 19:26906-17

21. Liu S, Yu WH, Li F, Zhao J, Yin RY, et al. 2018. Fertilizer application in rural cropland drives cadmium enrichment in bats dwelling in an urban area. Environmental pollution 242:970-5

22. Mareque C, da Silva TF, Vollu RE, Beracochea M, Seldin L, Battistoni F. 2018. The Endophytic Bacterial Microbiota Associated with Sweet Sorghum (Sorghum bicolor) Is Modulated by the Application of Chemical $\mathrm{N}$ Fertilizer to the Field. International journal of genomics 2018:7403670

23. Huang G, Ding C, Zhou Z, Zhang T, Wang X. 2019. A tillering application of zinc fertilizer based on basal stabilization reduces $\mathrm{Cd}$ accumulation in rice (Oryza sativa L.). Ecotoxicology and environmental safety 167:338-44

24. Xu R, Tian H, Pan S, Prior SA, Feng Y, et al. 2018. Global ammonia emissions from synthetic nitrogen fertilizer applications in agricultural systems: empirical and process-based estimates and uncertainty. Global change biology

25. Song X, Liu M, Ju X, Gao B, Su F, et al. 2018. Nitrous Oxide Emissions Increase Exponentially When Optimum Nitrogen Fertilizer Rates Are Exceeded in the North China Plain. Environmental science \& technology

26. Shi XL, Zhang ZM, Dai LX, Zhang GC, Ci DW, et al. 2018. Effects of calcium fertilizer application on absorption and distribution of nutrients in peanut under salt stress. Ying yong sheng tai xue bao = The journal of applied ecology 29:3302-10

27. Abuley IK, Nielsen BJ, Hansen HH. 2018. The influence of timing the application of nitrogen fertilizer on early blight (Alternaria solani). Pest management science

28. Xie Y, Tang L, Han Y, Yang L, Xie G, et al. 2018. Reduction in nitrogen fertilizer applications by the use of polymer-coated urea: effect on maize yields and environmental impacts of nitrogen losses. Journal of the science of food and agriculture

29. Ward BK, Dufault RJ, Hassell R, Cutulle MA. 2018. Affinity of Hyperammonia-Producing Bacteria To Produce Bioammonium/Ammonia Utilizing Five Organic Nitrogen Substrates for Potential Use as an Organic Liquid Fertilizer. ACS omega 3:11817-22

30. Martey E. 2018. Welfare effect of organic fertilizer use in Ghana. Heliyon 4:e00844

31. He Z, Cai Y, Yang Z, Li P, Lei H, et al. 2018. A dual-signal readout enzyme-free immunosensor based on hybridization chain reaction-assisted formation of copper nanoparticles for the detection of microcystin-LR. Biosensors \& bioelectronics 126:151-9

32. Ramirez JD, Herrera G, Muskus C, Mendez C, Duque MC, Butcher R. 2018. Development of a Digital Droplet Polymerase Chain Reaction (ddPCR) assay to detect Leishmania DNA in samples from Cutaneous Leishmaniasis patients. International journal of infectious diseases : IJID : official publication of the International Society for Infectious Diseases

33. Fang J, Li L, Yang C, Chen J, Deng GJ, Gong H. 2018. Tandem Oxidative RingOpening/Cyclization Reaction in Seconds in Open Atmosphere for the Synthesis of 1-Tetralones in Water-Acetonitrile. Organic letters

34. Dutta A, Behera RK, Dutta SK, Das Adhikari S, Pradhan N. 2018. Annealing CsPbX3 (X $=\mathrm{Cl}$ and Br) Perovskite Nanocrystals at High Reaction Temperatures: Phase Change and Its Prevention. The journal of physical chemistry letters:6599-604

35. Wu X, Zhou L, Maiti R, Mou C, Pan L, Chi YR. 2018. Sulfinate and Carbene Co-catalyzed Rauhut-Currier Reaction for Enantioselective Access to Azepino[1,2-a]indole. Angewandte Chemie 
36. Mustehsan MH, Jahufar F, Arora S. 2018. A Diagnostically Challenging Infusion ReactionKounis, Takotsubo, or the ATAK! JAMA internal medicine

37. Zhang K, Song S, Yang L, Min Q, Wu X, Zhu JJ. 2018. Enhancing intracellular microRNA imaging: a new strategy combining double-channel exciting single colour fluorescence with the target cycling amplification reaction. Chemical communications

38. Li Y, Chu F, Liu Y, Kong Y, Tao Y, et al. 2018. An ultrafine ruthenium nanocrystal with extremely high activity for the hydrogen evolution reaction in both acidic and alkaline media. Chemical communications

39. Peng Q, Chen J, Ji H, Morita A, Ye S. 2018. Origin of the Overpotential for the Oxygen Evolution Reaction on a Well-defined Graphene Electrode Probed by in situ Sum Frequency Generation Vibrational Spectroscopy. Journal of the American Chemical Society

40. Rivero-Crespo MA, Mon M, Ferrando-Soria J, Lopes CW, Boronat M, et al. 2018. Confined Pt11+-water clusters in a MOF Catalyze the Low-Temperature Water-Gas Shift Reaction with both $\mathrm{CO} 2$ Oxygen Atoms Coming from Water. Angewandte Chemie

41. Dickel D, Gwaltney SR, Mun S, Baskes MI, Horstemeyer MF. 2018. A Dispersion-Corrected Modified Embedded-Atom Method Bond Order Interatomic Potential for Sulfur. The journal of physical chemistry. A

42. Hosseini SM, Razzaghi-Kashani M. 2018. Catalytic and networking effects of carbon black on the kinetics and conversion of sulfur vulcanization in styrene butadiene rubber. Soft matter

43. Bartlett MA, Sundermeyer J. 2018. Group 10 metal-thiocatecholate capped magnesium phthalocyanines - coupling chromophore and electron donor/acceptor entities and its impact on sulfur induced red-shifts. Dalton transactions

44. Serdyuk OP, Smolygina LD, Khristin MS. 2018. Membrane-Bound Bacteriophytochrome-Like Complex of Phototrophic Purple Non-Sulfur Bacterium Rhodopseudomonas palustris. Doklady. Biochemistry and biophysics 482:284-7

45. Yun J, Zhu C, Wang Q, Hu Q, Yang G. 2018. Catalytic conversions of atmospheric sulfur dioxide and formation of acid rain over mineral dusts: Molecular oxygen as the oxygen source. Chemosphere 217:18-25

46. Misslinger M, Lechner BE, Bacher K, Haas H. 2018. Iron-sensing is governed by mitochondrial, not by cytosolic iron-sulfur cluster biogenesis in Aspergillus fumigatus. Metallomics : integrated biometal science

47. Zhang P, Chen W, Liu M, Wu H. 2018. Base-Controlled Three Component Reactions of Amines, Elemental Sulfur, and Styrenes: Synthesis of Thioamides under Metal-Free Conditions. The Journal of organic chemistry

48. Menacher G, Balszuweit F, Lang S, Thiermann H, Kehe K, et al. 2018. Necrosulfonamide Unexpected effect in the course of a sulfur mustard intoxication. Chemico-biological interactions

49. El-Shewy KM, Kunbaz A, Gad MM, Al-Husseini MJ, Saad AM, et al. 2018. Hyperbaric oxygen and aerobic exercise in the long-term treatment of fibromyalgia: A narrative review. Biomedicine \& pharmacotherapy $=$ Biomedecine \& pharmacotherapie 109:629-38

50. Memar MY, Yekani M, Alizadeh N, Baghi HB. 2018. Hyperbaric oxygen therapy: Antimicrobial mechanisms and clinical application for infections. Biomedicine \& pharmacotherapy = Biomedecine \& pharmacotherapie 109:440-7

51. Kim J, Kim CY, Oh H, Ryu B, Kim U, et al. 2018. Trimethyltin chloride induces reactive oxygen species-mediated apoptosis in retinal cells during zebrafish eye development. The Science of the total environment 653:36-44

52. Luo R, Li M, Wang C, Zhang M, Nasir Khan MA, et al. 2018. Singlet oxygen-dominated nonradical oxidation process for efficient degradation of bisphenol A under high salinity condition. Water research 148:416-24

53. Xu X, Ding X, Yang X, Wang P, Li S, et al. 2018. Oxygen vacancy boosted photocatalytic decomposition of ciprofloxacin over Bi2MoO6: Oxygen vacancy engineering, biotoxicity evaluation and mechanism study. Journal of hazardous materials 364:691-9 
54. Nel J, Desmet CM, Driesschaert B, Saulnier P, Lemaire L, Gallez B. 2018. Preparation and evaluation of trityl-loaded lipid nanocapsules as oxygen sensors for Electron Paramagnetic Resonance oximetry. International journal of pharmaceutics

55. de Moura Alvorcem L, Britto R, Parmeggiani B, Glanzel NM, da Rosa-Junior NT, et al. 2018. Evidence that thiol group modification and reactive oxygen species are involved in hydrogen sulfide-induced mitochondrial permeability transition pore opening in rat cerebellum. Mitochondrion

56. Wang G, Zhang S, Qian R, Wen Z. 2018. Atomic-thick TiO2(B) nanosheets decorated with ultrafine $\mathrm{Co} 3 \mathrm{O} 4$ nanocrystals as a highly efficient catalyst for lithium-oxygen battery. ACS applied materials \& interfaces

57. Nurdin L, Spasyuk DM, Fairburn LK, Piers WE, Maron L. 2018. Oxygen-Oxygen Bond Cleavage and Formation in Co(II) Mediated Stoichiometric O2 Reduction via the Potential Intermediacy of a $\mathrm{Co}(\mathrm{IV})$ Oxyl Radical. Journal of the American Chemical Society

58. Mestre AS, Hesse F, Freire C, Ania CO, Carvalho AP. 2018. Chemically activated high grade nanoporous carbons from low density renewable biomass (Agave sisalana) for the removal of pharmaceuticals. Journal of colloid and interface science 536:681-93

59. Gao W, Chelikowsky JR. 2018. Accuracy of Partial Core Corrections using Fourier Transforms in Pseudopotential-Density Functional Theory. Journal of chemical theory and computation

60. Lee DJ, Woertz EN, Visotcky A, Wilk MA, Heitkotter H, et al. 2018. The Henle Fiber Layer in Albinism: Comparison to Normal and Relationship to Outer Nuclear Layer Thickness and Foveal Cone Density. Investigative ophthalmology \& visual science 59:5336-48

61. Duran I, Katzmann J, Martakis K, Stark C, Semler O, Schoenau E. 2018. Individualized evaluation of lumbar bone mineral density in children with cerebral palsy. Archives of osteoporosis 13:120

62. Tsujita M, Wolska A, Gutmann DAP, Remaley AT. 2018. Reconstituted Discoidal High-Density Lipoproteins: Bioinspired Nanodiscs with Many Unexpected Applications. Current atherosclerosis reports 20:59

63. Orford NR, Bailey M, Bellomo R, Pasco JA, Cooper DJ, Kotowicz MA. 2018. Changes in bone mineral density in women before critical illness: a matched control nested cohort study. Archives of osteoporosis 13:119

64. Crocker KC, Hunter MD. 2018. Social density, but not sex ratio, drives ecdysteroid hormone provisioning to eggs by female house crickets (Acheta domesticus). Ecology and evolution 8:10257-65

65. Campbell A, Dykes A, Mire P. 2018. Periodic, moderate water flow reversibly increases hair bundle density and size in Nematostella vectensis. The Journal of experimental biology

66. Toshima T, Yoshizumi T, Ikegami T, Harada N, Itoh S, et al. 2018. Impact of Osteopenia in Liver Cirrhosis: Special Reference to Standard Bone Mineral Density with Age. Anticancer research 38:6465-71

67. Pazarli AC, Ekiz T, Inonu Koseoglu H. 2018. Association Between 25-Hydroxyvitamin D and Bone Mineral Density in People With Obstructive Sleep Apnea Syndrome. Journal of clinical densitometry : the official journal of the International Society for Clinical Densitometry

68. Uzma S, Khan S, Murad W, Taimur N, Azizullah A. 2018. Phytotoxic effects of two commonly used laundry detergents on germination, growth, and biochemical characteristics of maize (Zea mays L.) seedlings. Environmental monitoring and assessment 190:651

69. Smirnova IA, Adelroth P, Brzezinski P. 2018. Extraction and liposome reconstitution of membrane proteins with their native lipids without the use of detergents. Scientific reports 8:14950

70. Erkine AM. 2018. 'Nonlinear' Biochemistry of Nucleosome Detergents. Trends in biochemical sciences 
71. Urner LH, Maier YB, Haag R, Pagel K. 2018. Exploring the Potential of Dendritic Oligoglycerol Detergents for Protein Mass Spectrometry. Journal of the American Society for Mass Spectrometry

72. Winter S, McDonagh G, Lappin D, Smith AJ. 2018. Assessing the efficacy and cost of detergents used in a primary care automated washer disinfector. British dental journal 225:315-9

73. Kurien BT, Thomas R, Payne A, Scofield RH. 2018. Heat/Pressure Treatment with Detergents Significantly Increases Curcumin Solubility and Stability: Its Use as an Environment-Friendly Protein Gel Stain. Methods in molecular biology 1853:237-46

74. Kampf G. 2018. The unknown role of disinfectant-detergents for failure of effective endoscope reprocessing. The Journal of hospital infection

75. Lenoir G, Dieudonne T, Lamy A, Lejeune M, Vazquez-Ibar JL, Montigny C. 2018. Screening of Detergents for Stabilization of Functional Membrane Proteins. Current protocols in protein science 93:e59

76. Yang P, Gao W, Shulman JE, Chen Y. 2018. Separation and identification of polymeric dispersants in detergents by two-dimensional liquid chromatography. Journal of chromatography. A 1566:111-7

77. Wieck S, Olsson O, Kummerer K, Klaschka U. 2018. Fragrance allergens in household detergents. Regulatory toxicology and pharmacology : RTP 97:163-9

78. Pal A, Nasker P, Paul S, Roy Chowdhury A, Sinha A, Das M. 2018. Strontium doped hydroxyapatite from Mercenaria clam shells: Synthesis, mechanical and bioactivity study. Journal of the mechanical behavior of biomedical materials 90:328-36

79. Mallavadhani UV, Chandrashekhar M, Shailaja K, Ramakrishna S. 2018. Design, synthesis, antiinflammatory, cytotoxic and cell based studies of some novel side chain analogues of myrrhanones A \& B isolated from the gum resin of Commiphora mukul. Bioorganic chemistry 82:306-23

80. Tanoli ST, Ramzan M, Hassan A, Sadiq A, Jan MS, et al. 2018. Design, synthesis and bioevaluation of tricyclic fused ring system as dual binding site acetylcholinesterase inhibitors. Bioorganic chemistry 83:336-47

81. Harahap, F. and Lubis, L. (2018) "Analysis of Heavy Metals Distribution in the River Town of Hamasaki's Rod Padangsidimpuan”, EKSAKTA: Berkala Ilmiah Bidang MIPA, 19(2), pp. 50-56. doi: https://doi.org/10.24036/eksakta/vol19-iss2/149.

82. Syafei, N., Hidayat, D., Emilliano, E. and Men, L. (2018) "Analysis Cracking Corrosion on Carbon Steel Pipes API 5L-X65 In Solution $7700 \mathrm{ml}$ Aquades, $250 \mathrm{ml}$ Acetic Acid and $50 \mathrm{ml}$ Ammonia with Gas CO2 and $\mathrm{H} 2 \mathrm{~S}$ in Saturation Condition", EKSAKTA: Berkala Ilmiah Bidang MIPA, 19(2), pp. 21-31. doi: https://doi.org/10.24036/eksakta/vol19-iss2/138.

83. Necol MR, Vela Gurovic MS, Ruiz Diaz S, Silbestri GF. 2018. Binding silver to chitooligosaccharides through N-heterocyclic carbenes: Synthesis and antimicrobial activity. Carbohydrate research 471:6-12

84. Feng C, Wang J, Tang Q, Zhong Z, Qiao S, et al. 2018. One-pot synthesis of glycosyl phenylthiosulfonates from sulfinate, $S$ and glycosyl bromides. Carbohydrate research 471:1-5

85. Sun L, Pu S, Li J, Cai J, Zhou B, et al. 2018. Size controllable one step synthesis of gold nanoparticles using carboxymethyl chitosan. International journal of biological macromolecules

86. Khawar A, Aslam Z, Zahir A, Akbar I, Abbas A. 2018. Synthesis of Femur extracted hydroxyapatite reinforced nanocomposite and its application for $\mathrm{Pb}(\mathrm{II})$ ions abatement from aqueous phase. International journal of biological macromolecules

87. Offei SD, Arman HD, Baig MO, Chavez LS, Paladini CA, Yoshimoto FK. 2018. Chemical Synthesis of 7-Oxygenated 12alpha-Hydroxy Steroid Derivatives to Enable the Biochemical Characterization of Cytochrome P450 8B1, the Oxysterol 12alpha-Hydroxylase Enzyme Implicated in Cardiovascular Health and Obesity. Steroids

88. Igarashi M, Watanabe K, Tsuduki T, Kimura I, Kubota N. 2018. NAPE-PLD controls OEA synthesis and fat absorption by regulating lipoprotein synthesis in an in vitro model of intestinal 
epithelial cells. FASEB journal : official publication of the Federation of American Societies for Experimental Biology:fj201801408R

89. Vidyasagar A, Shi J, Kreitmeier P, Reiser O. 2018. Bromo- or Methoxy-Group-Promoted Umpolung Electron Transfer Enabled, Visible-Light-Mediated Synthesis of 2-Substituted Indole3-glyoxylates. Organic letters

90. Marranzano M, Rosa R, Malaguarnera M, Palmeri R, Tessitori M, Barbera AC. 2018. Polyphenols: plant sources and food industry applications. Current pharmaceutical design

91. Long R, Yang J, Chen H, Li Q, Fang W, Wang L. 2018. Co-evolutionary simulation study of multiple stakeholders in the take-out waste recycling industry chain. Journal of environmental management 231:701-13

92. Nadin-Davis S, Pope L, Ogunremi D, Brooks BW, Devenish J. 2018. A real-time PCR regimen for testing of environmental samples for $<\mathrm{i}>$ Salmonella enterica $</ \mathrm{i}>$ subsp. $\langle\mathrm{i}>$ enterica $</ \mathrm{i}\rangle$ serovars of concern to the poultry industry with special focus on $<\mathrm{i}>$ Salmonella $</ \mathrm{i}>$ Enteritidis. Canadian journal of microbiology

93. Prabowo, H. (2018) "PENYELIDIKAN KELAYAKAN KIMIA DAN PENYEBARAN CADANGAN PASIR BESI DAERAH TIKU KABUPATEN AGAM UNTUK BAHAN BAKU SEMEN PADA PT. SEMEN PADANG”, EKSAKTA: Berkala Ilmiah Bidang MIPA, 19(1), pp. 39-42. doi: https://doi.org/10.24036/eksakta/vol19-iss 1/121.

94. Syafei, N. (2018) "Riset Material ANALISA FENOMENA KOROSI PELAT PIPA BAJA KARBON API 5L-X65 DALAM LARUTAN 7900 ML AIR LAUT DAN 100 ML AMONIAK PADA KONDISI GAS CO2 DAN H2S JENUH PADA SUHU RUANG.”, EKSAKTA: Berkala Ilmiah Bidang MIPA, 19(1), pp. 7-13. doi: https://doi.org/10.24036/eksakta/vol19-iss1/83.

95. Parbuntari, H., Prestica, Y., Gunawan, R., Nurman, M. and Adella, F. (2018) "Preliminary Phytochemical Screening (Qualitative Analysis) of Cacao Leaves (Theobroma cacao L.)", EKSAKTA: Berkala Ilmiah Bidang MIPA, 19(2), pp. 40-45. doi: https://doi.org/10.24036/eksakta/vol19-iss2/142.

96. Dinata, M. and Soehardi, F. (2018) "Factor Analysis of Physics Chemistry Waters that Affects Damage Safety Cliff on the Outskirts of River Siak", EKSAKTA: Berkala Ilmiah Bidang MIPA, 19(2), pp. 46-49. doi: https://doi.org/10.24036/eksakta/vol19-iss2/143.

97. Sofyanita, S. and Octaria, Z. (2018) "Fenthion Compound Degradation in the Pesticide Bayleton $500 \mathrm{ec}$ in Sonolysis, Ozonolysis and Sonozolysis with Addition of TiO2-anatase", EKSAKTA: Berkala Ilmiah Bidang MIPA, 19(2), pp. 70-79. doi: https://doi.org/10.24036/eksakta/vol19iss $2 / 153$.

98. Li X, Liu Q, Li W, Li Q, Qian Z, et al. 2018. A breakthrough in the artificial cultivation of Chinese cordyceps on a large-scale and its impact on science, the economy, and industry. Critical reviews in biotechnology:1-11

99. Elmariah S, Rao SV, Grines CL, Garratt KN, Caputo RP, et al. 2018. "How can SCAI and industry partners increase adherence and educate interventionalists on optimal medical therapy?". Catheterization and cardiovascular interventions : official journal of the Society for Cardiac Angiography \& Interventions

100. Perez TY, Chen MC, Chung PH, Shenot PJ. 2018. Leaders in Urologic Education and their Relationship to Industry: An Analysis of Sunshine Act Open Payments from 2014-2016. Urology

101. Saito S, Maeno T, Miyata Y, Maeno T. 2018. Follow-up survey of Japanese medical students' interactions with the pharmaceutical industry. PloS one 13:e0206543

102. Hale SE, Skulcova L, Pipal M, Cornelissen G, Oen AMP, et al. 2018. Monitoring wastewater discharge from the oil and gas industry using passive sampling and Danio rerio bioassay as complimentary tools. Chemosphere 216:404-12

103. Combs TR, Scott J, Jorski A, Heavener T, Vassar M. 2018. Evaluation of Industry Relationships Among Authors of Clinical Practice Guidelines in Gastroenterology. JAMA internal medicine

104. Fischer-Wright H. 2016. America's healthcare industry still afflicted with gender equality issues in leadership. MGMA connexion 16:6-7 
105. Ochola DO, Sharif R, Bedford JS, Keefe TJ, Kato TA, et al. 2018. Persistence of Gamma-H2AX Foci in Bronchial Cells Correlates with Susceptibility to Radiation Associated Lung Cancer in Mice. Radiation research

106. Vancamp E, Salgado R, Mulkens TH, Termote JL, Parizel PM. 2015. Bronchial Atresia. JBRBTR : organe de la Societe royale belge de radiologie 98:149-50

107. Lanotte S, Frognier R, Van Cutsem O, Mailleux P. 2015. Bronchial lipoma : an unusual cause of pleural empyema. JBR-BTR : organe de la Societe royale belge de radiologie 98:88-90

108. Syafei, N. (2017) "ANALISA FENOMENA KOROSI PELAT PIPA BAJA KARBON API 5LX65 DALAM LARUTAN 250 ML ASAM ASETAT DAN 4750 ML AQUADES PADA KONDISI GAS CO2 DAN H2S JENUH PADA SUHU RUANG”, EKSAKTA: Berkala Ilmiah Bidang MIPA, 18(02), pp. 113-120. doi: https://doi.org/10.24036/eksakta/vol18-iss02/63.

109. Tutuarima, T. (2017) "SIFAT FISIK DAN KIMIA MARMALADE JERUK KALAMANSI (Citrus microcarpa) : KAJIAN KONSENTRASI PEKTIN DAN SUKROSA Physical and Chemical Properties of Marmalade Citrus of Calamondin (Citrus microcarpa) : Study of Pectin and Sucrose Concentrations", EKSAKTA: Berkala Ilmiah Bidang MIPA, 18(02), pp. 164-172. doi: https://doi.org/10.24036/eksakta/vol18-iss02/73.

110. Ruswandi, R. (2018) "Determination of Fructose Content resulted by Inulin Hydrolysis with DNS as Oxidizer", EKSAKTA: Berkala Ilmiah Bidang MIPA, 19(1), pp. 14-23. doi: https://doi.org/10.24036/eksakta/vol19-iss1/102.

111. Sanjaya, H. (2018) "DEGRADASI METIL VIOLET MENGGUNAKAN KATALIS ZnO-TiO2 SECARA FOTOSONOLISIS”, EKSAKTA: Berkala Ilmiah Bidang MIPA, 19(1), pp. 91-99. doi: https://doi.org/10.24036/eksakta/vol19-iss1/131.

112. Hidayani, T. (2018) "GRAFTING POLIPROPILENA DENGAN MALEAT ANHIDRIDA SEBAGAI PENGIKAT SILANG DENGAN INISIATOR BENZOIL PEROKSIDA", EKSAKTA: Berkala Ilmiah Bidang MIPA, 19(1), pp. 56-62. doi: https://doi.org/10.24036/eksakta/vol19iss1/127.

113. Jiang D, Wang Z, Yu N, Shen C, Deng L, Guo Y. 2018. Airway Remodeling in Asthma: Evaluation in 5 Consecutive Bronchial Generations by Using High-Resolution Computed Tomography. Respiratory care 63:1399-406

114. Wang L, Feng X, Hu B, Xia Q, Ni X, Song Y. 2018. P2X4R promotes airway remodeling by acting on the phenotype switching of bronchial smooth muscle cells in rats. Purinergic signalling

115. Miki K, Miki M, Yoshimura K, Tsujino K, Kagawa H, et al. 2018. Improvement of exertional dyspnea and breathing pattern of inspiration to expiration after bronchial thermoplasty. Allergy, asthma, and clinical immunology : official journal of the Canadian Society of Allergy and Clinical Immunology 14:74

116. Mahapatra S, Mangla L, Talwar D. 2018. Bronchial purging: Atypical pulmonary sarcoidosis presenting with bronchorrhea. Lung India : official organ of Indian Chest Society 35:533-5

117. Chauhan U, Kumar S, Nandolia KK, Dev R, Saxena S. 2018. Bronchial artery embolization for treatment of hemoptysis caused by peripheral pulmonary hamartoma. Lung India : official organ of Indian Chest Society 35:530-1

118. Hashimoto Y. 2017. [Anesthetic Management for Patients with Bronchial Asthma]. Masui. The Japanese journal of anesthesiology 66:11-7

119. Springer DM, Cofta S, Juszkat R, Zabicki B, Gozdzik-Spychalska J, et al. 2018. The effectiveness of bronchial artery embolisation in patients with haemoptysis. Advances in respiratory medicine 86:220-6

120. Yang X, Wang S, Zhao X, Yan X, Xiao Z, et al. 2018. Regulating Fast Anionic Redox for HighVoltage Aqueous Hydrogen-Ion based Energy Storage. Angewandte Chemie

121. Kang BR, Anderson AJ, Kim YC. 2018. Hydrogen cyanide produced by $<\mathrm{i}\rangle\langle\mathrm{i}\rangle$ Pseudomonas chlororaphis $\langle\mathrm{i}\rangle\langle\mathrm{i}\rangle$ O6 is a key aphicidal metabolite. Canadian journal of microbiology

122. Ramirez BV, Benito RM, Torres-Arenas J, Benavides AL. 2018. Water phase transitions from the perspective of hydrogen-bond network analysis. Physical chemistry chemical physics : PCCP 
123. Zainul, R. (2016, December 18). Design and Modification of Copper Oxide Electrodes for Improving Conversion Coefficient Indoors Lights (PV-Cell) Photocells. https://doi.org/10.31227/osf.io/pgn84

124. Zainul, R. (2016, December 18). Design and Modification of Copper Oxide Electrodes for Improving Conversion Coefficient Indoors Lights (PV-Cell) Photocells. https://doi.org/10.31227/osf.io/pgn84

125. Zainul, R. (2016, September 24). Determination of the half-life and the quantum yield of $\mathrm{ZnO}$ semiconductor photocatalyst in humic acid. https://doi.org/10.31227/osf.io/e8a9x

126. Febriani, S. S., Yolanda, T., Arianti, V. A., \& Zainul, R. (2018, September 2). A Review Solid Stated : Principles and Methode. https://doi.org/10.31227/osf.io/7us4x

127. Liza, Y. M., Yasin, R. C., Maidani, S. S., \& Zainul, R. (2018, September 29). SOL GEL : PRINCIPLE AND TECHNIQUE (A REVIEW). https://doi.org/10.31227/osf.io/2cuh8

128. Hua C, Sheng F, Hu Q, Xu Z, Lu Y, Zheng YS. 2018. Dialkali-Metal Monochalcogenide Semiconductors with High Mobility and Tunable Magnetism. The journal of physical chemistry letters

129. Nissen SK, Brabrand M, Nickel CH, Kellett J, Cooksley T. 2018. Impaired mobility is associated with risk of ICU admission but not outcome after ICU treatment. Acta anaesthesiologica Scandinavica

130. Campuzano IDG, Sobott F, van Stipdonk MJ. 2018. Editorial and Review: 30th ASMS Sanibel Conference on Mass Spectrometry-Computational Modelling in Mass Spectrometry and Ion Mobility: Methods for Ion Structure and Reactivity Determination. Journal of the American Society for Mass Spectrometry

131. Horiza, H., Azhar, M. and Efendi, J. (2017) "EKSTRAKSI DAN KARAKTERISASI INULIN DARI UMBI DAHLIA (Dahlia sp.L) SEGAR DAN DISIMPAN", EKSAKTA: Berkala Ilmiah Bidang MIPA, 18(01), pp. 31-39. doi: https://doi.org/10.24036/eksakta/vol18-iss01/14.

132. Iryani, I., Iswendi, I. and Katrina, I. T. (2017) "UJI AKTIVITAS ANTI DIABETES MELLITUS SENYAWA METABOLIT SEKUNDER FRAKSI AIR DARI BERAS KETAN HITAM ( Oryza satival. Var glutinosa) PADA MENCIT PUTIH", EKSAKTA: Berkala Ilmiah Bidang MIPA, 18(01), pp. 54-60. doi: https://doi.org/10.24036/eksakta/vol18-iss01/17.

133. Suryelita, S., Etika, S. B. and Kurnia, N. S. (2017) "ISOLASI DAN KARAKTERISASI SENYAWA STEROID DARI DAUN CEMARA NATAL (Cupressus funebris End1.)", EKSAKTA: Berkala Ilmiah Bidang MIPA, 18(01), pp. 86-94. doi: https://doi.org/10.24036/eksakta/vol18-iss01/23.

134. Iskandar, I., Horiza, H. and Fauzi, N. (2017) "EFEKTIVITAS BUBUK BIJI PEPAYA (Carica Papaya Linnaeaus) SEBAGAI LARVASIDA ALAMI TERHADAP KEMATIAN LARVA AEDES AEGYPTY TAHUN 2015”, EKSAKTA: Berkala Ilmiah Bidang MIPA, 18(01), pp. 12 18. doi: https://doi.org/10.24036/eksakta/vol18-iss01/12.

135. Ramli, R., Jonuarti, R. and Hartono, A. (2017) "ANALISIS STRUKTUR NANO DARI LAPISAN TIPIS COBALT FERRITE YANG DIPREPARASI DENGAN METODE SPUTTERING", EKSAKTA: Berkala Ilmiah Bidang MIPA, 18(01), pp. 46-53. doi: https://doi.org/10.24036/eksakta/vol18-iss01/16.

136. 2018. Correction for Belsky et al., Genetic analysis of social-class mobility in five longitudinal studies. Proceedings of the National Academy of Sciences of the United States of America

137. Guerra ZF, Bellose LC, Coelho de Morais Faria CD, Lucchetti G. 2018. The effects of mental practice based on motor imagery for mobility recovery after subacute stroke: Protocol for a randomized controlled trial. Complementary therapies in clinical practice 33:36-42

138. Salas-Wright CP, Oh S, Vaughn MG, Cohen M, Scott JC, Amodeo M. 2018. Trends and drugrelated correlates in residential mobility among young adults in the United States, 2003-2016. Addictive behaviors 90:146-50 
139. Xiang TX, Anderson BD. 2018. Effects Of Molecular Interactions On Miscibility And Mobility Of Ibuprofen In Amorphous Solid Dispersions With Various Polymers. Journal of pharmaceutical sciences

140. Wang GH, Wang JJ, Yue B, Du X, Du HH, et al. 2018. High mobility group box 2 of black rockfish Sebastes schlegelii: Gene cloning, immunoregulatory properties and antibacterial effect. Fish \& shellfish immunology 84:719-25

141. Xia J, Xue JY, Chen K, Lin ZY, Wu WJ, Zhao QF. 2018. [The role of high-mobility group box protein 1 in the signaling pathways of myocardial ischemia-reperfusion injury in rats]. Zhonghua yi xue za zhi 98:3268-73

142. Mendoza S, Armbrister AN, Abraido-Lanza AF. 2018. Are you better off? Perceptions of social mobility and satisfaction with care among Latina immigrants in the U.S. Social science \& medicine 219:54-60

143. Sanjaya, H. (2017) "DEGRADASI METHYLENE BLUE MENGGUNAKAN KATALIS ZnOPEG DENGAN METODE FOTOSONOLISIS", EKSAKTA: Berkala Ilmiah Bidang MIPA, 18(02), pp. 21-29. doi: https://doi.org/10.24036/eksakta/vol18-iss02/45.

144. Ningsih, S. K. (2017) "SINTESIS DAN KARAKTERISASI NANOPARTIKEL ZnO DOPED Cu2+ MELALUI METODA SOL-GEL”, EKSAKTA: Berkala Ilmiah Bidang MIPA, 18(02), pp. 39-51. doi: https://doi.org/10.24036/eksakta/vol18-iss02/51.

145. Saiya, A. (2017) “ANALISIS RESIDU KLORPIRIFOS DALAM SAYURAN KUBIS DENGAN METODE HPLC DI BEBERAPA PASAR TRADISIONAL DI SULAWESI UTARA", EKSAKTA: Berkala Ilmiah Bidang MIPA, 18(02), pp. 77-85. doi: https://doi.org/10.24036/eksakta/vol18-iss02/57.

146. Hunter MV, Willoughby PM, Bruce AEE, Fernandez-Gonzalez R. 2018. Oxidative Stress Orchestrates Cell Polarity to Promote Embryonic Wound Healing. Developmental cell 47:377-87 e4

147. Yao YF, Chou KP, Lin HH, Chen CC, Kiang YW, Yang CCC. 2018. Polarity Control in Growing Highly Ga-doped ZnO Nanowires with Vapor-liquid-solid Process. ACS applied materials \& interfaces

148. Ambrozkiewicz MC, Schwark M, Kishimoto-Suga M, Borisova E, Hori K, et al. 2018. Polarity Acquisition in Cortical Neurons Is Driven by Synergistic Action of Sox9-Regulated Wwp1 and Wwp2 E3 Ubiquitin Ligases and Intronic miR-140. Neuron

149. Chen WT, Hsu WT, Yen MH, Changou CA, Han CL, et al. 2018. Alteration of mesenchymal stem cells polarity by laminar shear stimulation promoting beta-catenin nuclear localization. Biomaterials 190-191:1-10

150. Garrido-Jimenez S, Roman AC, Alvarez-Barrientos A, Carvajal-Gonzalez JM. 2018. Centriole planar polarity assessment in Drosophila wings. Development

151. Mohanan A, Nickerson MT, Ghosh S. 2018. Oxidative stability of flaxseed oil: Effect of hydrophilic, hydrophobic and intermediate polarity antioxidants. Food chemistry 266:524-33

152. Li LM, Violante IR, Leech R, Ross E, Hampshire A, et al. 2018. Brain state and polarity dependent modulation of brain networks by transcranial direct current stimulation. Human brain mapping

153. Costa Pinto E, Xu C, Cabral LM, Armstrong DW, de Sousa VP. 2018. Sensitive detection of topiramate degradation products by HPLC-ESI-MS using ion-pairing reagents and polarity switching. Rapid communications in mass spectrometry : RCM

154. Li Y, Junge JA, Arnesano C, Gross GG, Miner JH, et al. 2018. Discs large 1 controls daughtercell polarity after cytokinesis in vertebrate morphogenesis. Proceedings of the National Academy of Sciences of the United States of America

155. Hollande L, Domenek S, Allais F. 2018. Chemo-Enzymatic Synthesis of Renewable StericallyHindered Phenolic Antioxidants with Tunable Polarity from Lignocellulose and Vegetal Oil Components. International journal of molecular sciences 19 
156. Zainul, R. (2016, November 19). Effect of Temperature and Particle Motion against the ability of ZnO Semiconductor Photocatalyst in Humic Acid. https://doi.org/10.31227/osf.io/wnygb

157. Dinata, A. A., Rosyadi, A. M., Hamid, S., \& Zainul, R. (2018, August 31). A Review CHEMICAL VAPOR DEPOSITION : PROCESS AND APPLICATION. https://doi.org/10.31227/osf.io/yfeau

158. Putri, D. F., Ritonga, H. M., Murdiati, V., \& Zainul, R. (2018, August 31). A REVIEW WHAT IS HYDROTHERMAL ?. https://doi.org/10.31227/osf.io/dm56c

159. Awalliyah, A., Ikhwan, H., Nugiasari, V., \& Zainul, R. (2018, August 31). A REVIEW PRINSIP DASAR MILLING DALAM SINTESIS MATERIAL. https://doi.org/10.31227/osf.io/9xsqe

160. Candani, D., Ulfah, M., Noviana, W., \& Zainul, R. (2018, September 1). A Review Pemanfaatan Teknologi Sonikasi. https://doi.org/10.31227/osf.io/uxknv

161. Pellegrino R, Jones JD, Shupe GE, Luckett CR. 2018. Sensitivity to viscosity changes and subsequent estimates of satiety across different senses. Appetite 133:101-6

162. Kampf N, Wachtel EJ, Zilman A, Ben-Shalom N, Klein J. 2018. Anomalous viscosity-time behavior of polysaccharide dispersions. The Journal of chemical physics 149:163320

163. Zhang Y, Moins S, Coulembier O, Seveno D, De Coninck J. 2018. Capillary rise of polydimethylsiloxane around a poly(ethylene terephthalate) fiber versus viscosity: Existence of a sharp transition in the dynamic wetting behavior. Journal of colloid and interface science 536:499-506

164. Gitis M. 2018. On the interpretation of shear viscosity ultrasonic measurements. Ultrasonics 93:1-6

165. Leuzinger S, Steingotter A, Nystrom L. 2018. Viscosity of Cereal beta-Glucan in the Gastrointestinal Tract. Chimia 72:733-5

166. Kim DS, Lee JK. 2019. Effect of Slurry Viscosity and Dispersant Agent on the Sintering of 3YTZP Ceramics Fabricated by Slip Casting. Journal of nanoscience and nanotechnology 19:111821

167. Sun W, Cui JX, Ma LL, Lu ZL, Gong B, et al. 2018. Imaging nucleus viscosity and G-quadruplex DNA in living cells using a nucleus-targeting two-photon fluorescent probe. The Analyst

168. Wylie L, Seeger ZL, Hancock AN, Izgorodina EI. 2018. Increased stability of nitroxide radicals in ionic liquids: more than a viscosity effect. Physical chemistry chemical physics : PCCP

169. Sia I, Crary MA, Kairalla J, Carnaby GD, Sheplak M, McCulloch T. 2018. Bolus volume and viscosity effects on pharyngeal swallowing power-How physiological bolus accommodation affects bolus dynamics. Neurogastroenterology and motility : the official journal of the European Gastrointestinal Motility Society:e13481

170. Wu HC, Lee LC, Wang WJ. 2018. Plasmapheresis for hypertriglyceridemia: The association between blood viscosity and triglyceride clearance rate. Journal of clinical laboratory analysis:e22688

171. Fatimah, P., Jumalia, R., Novianti, E. R., \& Zainul, R. (2018, August 31). A REVIEW Teknik Blended : Prinsip dan Dasar-Dasar. https://doi.org/10.31227/osf.io/tm2w4

172. Zainul, R., Oktavia, B., Dewata, I., \& efendi, j. (2017, February 4). Studi Dinamika Molekular dan Kinetika Reaksi pada Pembelahan Molekul Air untuk Produksi Gas Hidrogen. https://doi.org/10.31227/osf.io/876s3

173. Zainul, R., Alif, A., Aziz, H., Arief, S., \& s. (2015, October 22). Photoelectrosplitting Water Mechanism at Carbon Electrode Surface using Indoor lights. https://doi.org/10.31227/osf.io/vcxq8

174. Zainul, R., Alif, A., Aziz, H., Arief, S., \& s. (2015, October 22). Photoelectrosplitting Water Mechanism at Carbon Electrode Surface using Indoor lights. https://doi.org/10.31227/osf.io/vexq8

175. M., Yani, S. R., \& Zainul, R. (2017, September 4). Aktivasi Tanah Napa dan Pengaruhnya Terhadap Adsorpsi Ion Timbal (II)/ Pb2+. https://doi.org/10.31227/osf.io/ps523 
176. de Castilhos MBM, Del Bianchi VL, Gomez-Alonso S, Garcia-Romero E, Hermosin-Gutierrez I. 2019. Sensory descriptive and comprehensive GC-MS as suitable tools to characterize the effects of alternative winemaking procedures on wine aroma. Part I: BRS Carmem and BRS Violeta. Food chemistry 272:462-70

177. Murray MM, Eardley AF, Edginton T, Oyekan R, Smyth E, Matusz PJ. 2018. Sensory dominance and multisensory integration as screening tools in aging. Scientific reports 8:8901

178. Dugas C, Simard MN, Fombonne E, Couture M. 2018. Comparison of Two Tools to Assess Sensory Features in Children With Autism Spectrum Disorder. The American journal of occupational therapy : official publication of the American Occupational Therapy Association 72:7201195010p1-p9

179. Nicolli KP, Biasoto ACT, Souza-Silva EA, Guerra CC, Dos Santos HP, et al. 2018. Sensory, olfactometry and comprehensive two-dimensional gas chromatography analyses as appropriate tools to characterize the effects of vine management on wine aroma. Food chemistry 243:103-17

180. Liu L, Sham TK, Han W. 2013. Investigation on the electronic structure of BN nanosheets synthesized via carbon-substitution reaction: the arrangement of B, N, C and $\mathrm{O}$ atoms. Physical chemistry chemical physics : PCCP 15:6929-34

181. Flemming A, Kockerling M. 2009. Niobium alcoholate clusters with an octahedral arrangement of metal atoms: $[\mathrm{K}(\mathrm{CH} 3 \mathrm{OH}) 4] 2 \quad[\mathrm{Nb} 6(\mathrm{OCH} 3) 18]$ and $[\mathrm{Na}([18] \mathrm{crown}-6)(\mathrm{C} 2 \mathrm{H} 5 \mathrm{OH}) 2] 2$ [Nb6(OC2H5)12(NCS)6]. Angewandte Chemie 48:2605-8

182. Ran Q, Xu X, Dey P, Yu S, Lu Y, et al. 2018. Interaction of human serum albumin with dendritic polyglycerol sulfate: Rationalizing the thermodynamics of binding. The Journal of chemical physics 149:163324

183. Dutt AK. 2018. Local Concentration Deviations in a Glycolytic Model of Non-Equilibrium Thermodynamics: Emergence of Bi-Stability from Thermodynamic Theories Due to Violation of Lyapunov Stability Theory. The journal of physical chemistry. B

184. Marques BS, Frantz TS, Sant'Anna Cadaval Junior TR, de Almeida Pinto LA, Dotto GL. 2018. Adsorption of a textile dye onto piacava fibers: kinetic, equilibrium, thermodynamics, and application in simulated effluents. Environmental science and pollution research international

185. Deblonde GJ, Lohrey TD, Booth CH, Carter KP, Parker BF, et al. 2018. Solution Thermodynamics and Kinetics of Metal Complexation with a Hydroxypyridinone Chelator Designed for Thorium-227 Targeted Alpha Therapy. Inorganic chemistry

186. P, O. M., A, L. G., S, A. Y. M., \& Zainul, R. (2018, September 1). A Review Grinding : Teknik dan Prinsip Dasar pada Pengolahan Material. https://doi.org/10.31227/osf.io/trv4q

187. H., Sanjaya, H., \& Zainul, R. (2016, August 30). Synthesis and Electrical Properties of ZnO-ITO and Al-ITO thin Film by Spin Coating Technique Through Sol Gel Process. https://doi.org/10.31227/osf.io/unrt4

188. M., Sanjaya, H., \& Zainul, R. (2015, December 30). Characterization of napa soil and adsorption of $\mathrm{Pb}$ (II) from aqueous solutions using on column method. https://doi.org/10.31227/osf.io/t8fh9

189. chaidir, z., Fadjria, N., A., \& Zainul, R. (2016, December 5). ISOLATION AND MOLECULAR IDENTIFICATION OF FRESHWATER MICROALGAE IN MANINJAU LAKE WEST SUMATERA. https://doi.org/10.31227/osf.io/nbcuf

190. chaidir, z., Zainul, R., Nurakhbari, D., \& Salim, M. (2016, September 24). Optimization of Spirulina Platensis Culture for Antioxidant Production. https://doi.org/10.17605/OSF.IO/FD6E4

191. Basurto E, Haro-Perez C, Vargas CA, Odriozola G. 2018. Massive replica exchange Monte Carlo algorithm: a tool to access high pressure thermodynamics of hard systems. Physical chemistry chemical physics : PCCP

192. Marinova V, Wood GPF, Marziano I, Salvalaglio M. 2018. Dynamics and thermodynamics of Ibuprofen conformational isomerism at the crystal/solution interface. Journal of chemical theory and computation 
193. Bennett JW, Jones DT, Hamers RJ, Mason SE. 2018. First-Principles and Thermodynamics Study of Compositionally Tuned Complex Metal Oxides: Cation Release from the (001) Surface of MnRich Lithium Nickel Manganese Cobalt Oxide. Inorganic chemistry 57:13300-11

194. Astumian RD. 2018. Trajectory and Cycle-Based Thermodynamics and Kinetics of Molecular Machines: The Importance of Microscopic Reversibility. Accounts of chemical research

195. Ji CL, Xie PP, Hong X. 2018. Computational Study of Mechanism and Thermodynamics of $\mathrm{Ni} / \mathrm{IPr}-\mathrm{Catalyzed} \mathrm{Amidation} \mathrm{of} \mathrm{Esters.} \mathrm{Molecules} 23$

196. Li P, Jia X, Pan X, Shao Y, Mei Y. 2018. Accelerated Computation of Free Energy Profile at ab Initio Quantum Mechanical/Molecular Mechanics Accuracy via a Semi-Empirical Reference Potential. I. Weighted Thermodynamics Perturbation. Journal of chemical theory and computation

197. Presto S, Artini C, Pani M, Carnasciali MM, Massardo S, Viviani M. 2018. Ionic conductivity and local structural features in $\mathrm{Ce} 1-\mathrm{xSmxO}-\mathrm{x} / 2$. Physical chemistry chemical physics : $P C C P$

198. Yamamoto S, Fujiwara H, Maruyama K, Tanaka Y, Kinoshita M, Suzuki S. 2018. Simultaneous determination of inorganic anions and cations in water and biological samples by capillary electrophoresis with a capacitive coupled contactless conductivity detector using capillary filling method. Analytical sciences : the international journal of the Japan Society for Analytical Chemistry

199. Pankratova EV, Kalyakulina AI, Krivonosov MI, Denisov SV, Taute KM, Zaburdaev VY. 2018. Chemotactic drift speed for bacterial motility pattern with two alternating turning events. PloS one 13:e0190434

200. Dirisaglik F, Bakan G, Jurado Z, Muneer S, Akbulut M, et al. 2015. High speed, high temperature electrical characterization of phase change materials: metastable phases, crystallization dynamics, and resistance drift. Nanoscale 7:16625-30

201. Zainul R, Oktavia B, Dewata I, Efendi J. Thermal and Surface Evaluation on The Process of Forming a $\mathrm{Cu} 2 \mathrm{O} / \mathrm{CuO}$ Semiconductor Photocatalyst on a Thin Copper Plate. Proc. IOP Conference Series: Materials Science and Engineering, 2018, 335:012039: IOP Publishing

202. Zainul R, Alif A, Aziz H, Arief S, Dradjad S, Munaf E. 2015. Design of photovoltaic cell with copper oxide electrode by using indoor lights. RESEARCH JOURNAL OF PHARMACEUTICAL BIOLOGICAL AND CHEMICAL SCIENCES 6:353-61

203. Mawardi M, Deyundha D, Zainul R. Characterization of PCC Cement by Addition of Napa Soil from Subdistrict Sarilamak 50 Kota District as Alternative Additional Material for Semen Padang. Proc. IOP Conference Series: Materials Science and Engineering, 2018, 335:012034: IOP Publishing

204. Anhar A, Sumarmin R, Zainul R. 2016. Measurement of Glycemic Index of West Sumatera Local Rice Genotypes for Healthy Food Selection.

205. Zainul R, Dewata I. 2015. Determination of pH-BOD-COD and degradation in batang arau watersheds at Padang city.

206. Zhang J, Rowe JB. 2014. Dissociable mechanisms of speed-accuracy tradeoff during visual perceptual learning are revealed by a hierarchical drift-diffusion model. Frontiers in neuroscience $8: 69$

207. Husain M, Boudier T, Paul-Gilloteaux P, Casuso I, Scheuring S. 2012. Software for drift compensation, particle tracking and particle analysis of high-speed atomic force microscopy image series. Journal of molecular recognition : JMR 25:292-8

208. Fordell T, Miranda M, Arnold CL, L'Huillier A. 2011. High-speed carrier-envelope phase drift detection of amplified laser pulses. Optics express 19:23652-7

209. Newbury DE. 2006. Electron-excited energy dispersive X-ray spectrometry at high speed and at high resolution: silicon drift detectors and microcalorimeters. Microscopy and microanalysis : the official journal of Microscopy Society of America, Microbeam Analysis Society, Microscopical Society of Canada 12:527-37 
210. Brown LE, Rosenbaum DA, Sainburg RL. 2003. Movement speed effects on limb position drift. Experimental brain research 153:266-74

211. van Outersterp RE, Martens J, Berden G, Steill JD, Oomens J, Rijs AM. 2018. Structural characterization of nucleotide 5'-triphosphates by infrared ion spectroscopy and theoretical studies. Physical chemistry chemical physics : PCCP

212. Xu Y, Wang D, Tang L, Wang J. 2018. Separation and Characterization of Unknown Impurities and Isomers in Cefminox Sodium and Study of the Forming Mechanisms of Impurities by Liquid Chromatography Coupled with Ion Trap/Time-Of-Flight Mass Spectrometry. Journal of chromatographic science

213. Liyanage OT, Brantley MR, Calixte EI, Solouki T, Shuford KL, Gallagher ES. 2018. Characterization of Electrospray Ionization (ESI) Parameters on In-ESI Hydrogen/Deuterium Exchange of Carbohydrate-Metal Ion Adducts. Journal of the American Society for Mass Spectrometry

214. Suzuki S, Ranade S, Osaki K, Ito S, Shigenari A, et al. 2018. Reference Grade Characterization of Polymorphisms in Full-Length HLA Class I and II Genes With Short-Read Sequencing on the ION PGM System and Long-Reads Generated by Single Molecule, Real-Time Sequencing on the PacBio Platform. Frontiers in immunology 9:2294

215. Harrison JA, Kelso C, Pukala TL, Beck JL. 2018. Conditions for Analysis of Native Protein Structures Using Uniform Field Drift Tube Ion Mobility Mass Spectrometry and Characterization of Stable Calibrants for TWIM-MS. Journal of the American Society for Mass Spectrometry

216. Zuber J, Rathsack P, Otto M. 2018. Structural Characterization of Acidic Compounds in Pyrolysis Liquids Using Collision-Induced Dissociation and Fourier Transform Ion Cyclotron Resonance Mass Spectrometry. Analytical chemistry 90:12655-62

217. Li J, Yuan H, Yao Y, Hua J, Yang Y, et al. 2019. Rapid volatiles fingerprinting by dopantassisted positive photoionization ion mobility spectrometry for discrimination and characterization of Green Tea aromas. Talanta 191:39-45

218. Huang W, Seetasang S, Dasgupta PK. 2018. Characterization of ion exchange functionalized cyclic olefin polymer open tubular columns. Analytica chimica acta 1036:187-94

219. Saber M, Takahashi F, Yoshikawa K. 2018. Characterization and application of microalgae hydrochar as a low-cost adsorbent for $\mathrm{Cu}(\mathrm{II})$ ion removal from aqueous solutions. Environmental science and pollution research international 25:32721-34

220. Lemke T, Peter C, Kukharenko O. 2018. Efficient Sampling and Characterization of Free Energy Landscapes of Ion-Peptide Systems. Journal of chemical theory and computation

221. RoyChowdhury A, Sarkar D, Datta R. 2018. Removal of Acidity and Metals from Acid Mine Drainage-Impacted Water using Industrial Byproducts. Environmental management

222. Gittus OR, von Rudorff GF, Rosso KM, Blumberger J. 2018. Acidity Constants of the HematiteLiquid Water Interface from Ab Initio Molecular Dynamics. The journal of physical chemistry letters 9:5574-82

223. Wang H, Ding J, Xu J, Wen J, Han J, et al. 2019. Aerosols in an arid environment: The role of aerosol water content, particulate acidity, precursors, and relative humidity on secondary inorganic aerosols. The Science of the total environment 646:564-72

224. Vuorenmaa J, Augustaitis A, Beudert B, Bochenek W, Clarke N, et al. 2018. Long-term changes (1990-2015) in the atmospheric deposition and runoff water chemistry of sulphate, inorganic nitrogen and acidity for forested catchments in Europe in relation to changes in emissions and hydrometeorological conditions. The Science of the total environment 625:1129-45

225. Eugene AJ, Pillar EA, Colussi AJ, Guzman MI. 2018. Enhanced Acidity of Acetic and Pyruvic Acids on the Surface of Water. Langmuir : the ACS journal of surfaces and colloids 34:9307-13

226. Zainul R, Alif A, Aziz H, Arief S. 2015. DISAIN GEOMETRI REAKTOR FOTOSEL CAHAYA RUANG. Jurnal Riset Kimia 8:131

227. Zainul R, Alif A, Aziz H, Arief S, Darajat S. 2015. Modifikasi dan Karakteristik IV Sel Fotovoltaik Cu2o/Cu-Gel Na2so4 Melalui Iluminasi Lampu Neon. EKSAKTA 2:50 
228. Yasthopi A. 2015. Photoelectrosplitting water for hydrogen production using illumination of indoor lights. Journal of Chemical and Pharmaceutical Research 7:246-56

229. Zainul R. 2015. Disain dan Modifikasi Kolektor dan Reflektor Cahaya pada Panel Sel Surya $\mathrm{Al} / \mathrm{Cu} 2 \mathrm{O}-\mathrm{Gel} \mathrm{Na} 2 \mathrm{SO} 4$.

230. Mawardi Anwar E, Kosela S, Wibowo W, Zainul R. 2015. Study of Pb (II) biosorption from aqueous solution using immobilized Spirogyra subsalsa biomass. Journal of Chemical and Pharmaceutical Research 7:715-22

231. Montero-Campillo MM, Alkorta I, Elguero J. 2018. Enhancement of Thermodynamic Gas-Phase Acidity and Basicity of Water by Means of Secondary Interactions. Chemphyschem : a European journal of chemical physics and physical chemistry 19:2486-91

232. Fatemeh M, Marjan S, Homa N, Mahsa S. 2017. CPP-ACP: Effect on Dental Plaque Acidity after Water Rinsing Following Topical Fluoride Therapy. The Journal of clinical pediatric dentistry 41:22-6

233. Brereton KR, Bellows SM, Fallah H, Lopez AA, Adams RM, et al. 2016. Aqueous Hydricity from Calculations of Reduction Potential and Acidity in Water. The journal of physical chemistry. B 120:12911-9

234. Trummal A, Lipping L, Kaljurand I, Koppel IA, Leito I. 2016. Acidity of Strong Acids in Water and Dimethyl Sulfoxide. The journal of physical chemistry. A 120:3663-9

235. Galan A, Losada-Barreiro S, Bravo-Diaz C. 2016. A Physicochemical Study of the Effects of Acidity on the Distribution and Antioxidant Efficiency of Trolox in Olive Oil-in-Water Emulsions. Chemphyschem : a European journal of chemical physics and physical chemistry 17:296-304

236. Divakar P, Yin K, Wegst UGK. 2018. Anisotropic freeze-cast collagen scaffolds for tissue regeneration: How processing conditions affect structure and properties in the dry and fully hydrated states. Journal of the mechanical behavior of biomedical materials 90:350-64

237. Peng W, Cheng D, Song C. 2018. One-time-pad cryptography scheme based on a threedimensional DNA self-assembly pyramid structure. PloS one 13:e0206612

238. Bujak M. 2018. Melting point, molecular symmetry and aggregation of tetrachlorobenzene isomers: the role of halogen bonding. Acta crystallographica Section B, Structural science, crystal engineering and materials 74:458-66

239. Tang Y, Zhang L. 2018. Effect of Thermal Vacancy on Thermodynamic Behaviors in BCC W Close to Melting Point: A Thermodynamic Study. Materials 11

240. Kim HW, Kim TY, Park HK, You I, Kwak J, et al. 2018. Hygroscopic Auxetic On-Skin Sensors for Easy-to-Handle Repeated Daily Use. ACS applied materials \& interfaces

241. Desy Kurniawati I, Harmiwati SS, Chaidir Z, Munaf E. Rahmiana Zein, Hermansyah Aziz, Rahadian Zainul. 2015. Biosorption of $\mathrm{Pb}$ (II) from Aqueous Solutions Using Column Method by Lengkeng (Euphoria logan lour) Seed and Shell. Journal of Chemical and Pharmaceutical Research 7:872-7

242. Zainul R, Nurakhbari D, Salim M. Optimization of Spirulina Platensis Culture for Antioxidant Production.

243. Wu FM, Wang N, Pang SF, Zhang YH. 2019. Hygroscopic behavior and fractional crystallization of mixed (NH4)2SO4/glutaric acid aerosols by vacuum FTIR. Spectrochimica acta. Part A, Molecular and biomolecular spectroscopy 208:255-61

244. Marinos R, Campbell JL, Driscoll CT, Likens G, McDowell WH, et al. 2018. Give and Take: A Watershed Acid Rain Mitigation Experiment Increases Baseflow Nitrogen Retention but Increases Stormflow Nitrogen Export. Environmental science \& technology

245. Morgese G, Gombert Y, Ramakrishna SN, Benetti EM. 2018. Mixing PEG and Poly(2-Alkyl-2Oxazoline)s Enhances Hydration and Viscoelasticity of Polymer Brushes and Determines Their Nanotribological and Antifouling Properties. ACS applied materials \& interfaces

246. Rosinger AY, Chang AM, Buxton O, Li J, Wu S, Gao X. 2018. Short sleep duration is associated with inadequate hydration: Cross-cultural evidence from US and Chinese adults. Sleep 
247. Cuhadar C, Kim SG, Yang JM, Seo JY, Lee D, Park NG. 2018. All-Inorganic Bismuth Halide Perovskite-Like Materials A3Bi2I9 and A3Bi1.8Na0.2I8.6 (A = Rb and Cs) for Low-Voltage Switching Resistive Memory. ACS applied materials \& interfaces 10:29741-9

248. Shizgal BD. 2018. Kappa and other nonequilibrium distributions from the Fokker-Planck equation and the relationship to Tsallis entropy. Physical review. E 97:052144

249. Chen LJ, Wang S, Wilson LB, Schwartz S, Bessho N, et al. 2018. Electron Bulk Acceleration and Thermalization at Earth's Quasiperpendicular Bow Shock. Physical review letters 120:225101

250. Park J, Hadamek T, Posadas AB, Cha E, Demkov AA, Hwang H. 2017. Multi-layered $\mathrm{NiOy} / \mathrm{NbOx} / \mathrm{NiOy}$ fast drift-free threshold switch with high Ion/Ioff ratio for selector application. Scientific reports 7:4068

251. chaidir, z., Zainul, R., Nurakhbari, D., \& Salim, M. (2016, September 24). Optimization of Spirulina Platensis Culture for Antioxidant Production. https://doi.org/10.17605/OSF.IO/FD6E4

252. Yefremova Y, Opuni KFM, Danquah BD, Thiesen HJ, Glocker MO. 2017. Intact Transition Epitope Mapping (ITEM). Journal of the American Society for Mass Spectrometry 28:1612-22

253. Zhu Q, Zhang Q, Zhang N, Gong M. 2017. Alternate injections coupled with flow-gated capillary electrophoresis for rapid and accurate quantitative analysis of urine samples. Analytica chimica acta 978:55-60 